DIW BERLIN

Discussion

Papers
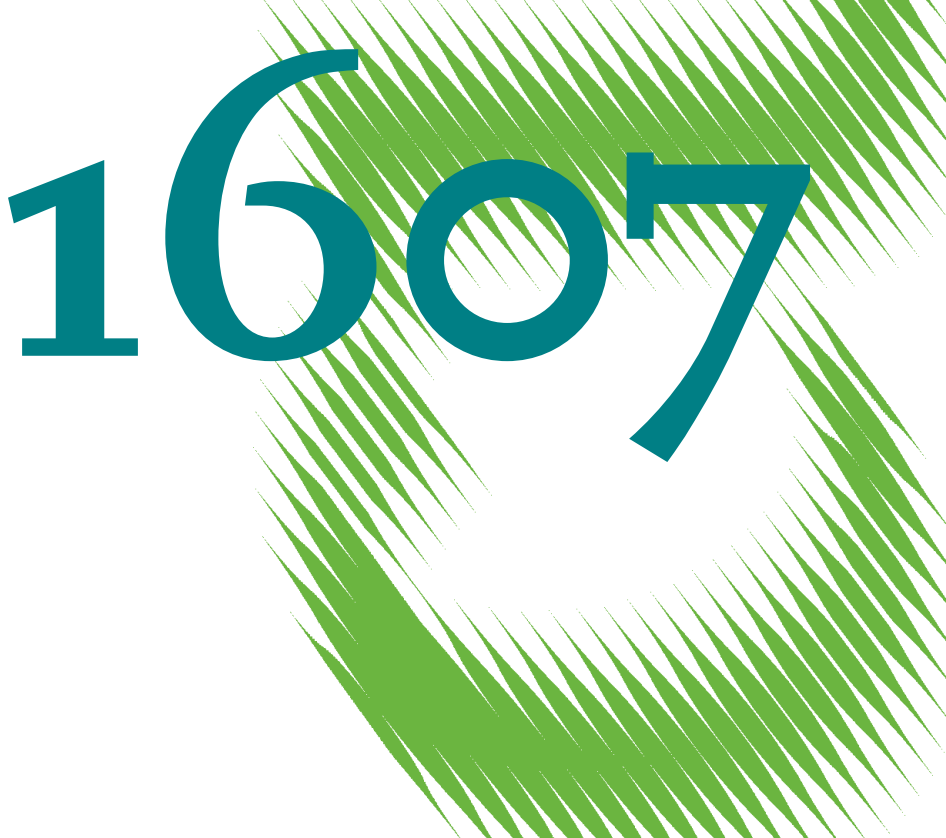

Political Corruption in the Execution of Public Contracts 
Opinions expressed in this paper are those of the author(s) and do not necessarily reflect views of the institute.

IMPRESSUM

(C) DIW Berlin, 2016

DIW Berlin

German Institute for Economic Research

Mohrenstr. 58

10117 Berlin

Tel. +49 (30) $89789-0$

Fax +49 (30) $89789-200$

http://www.diw.de

ISSN electronic edition 1619-4535

Papers can be downloaded free of charge from the DIW Berlin website:

http://www.diw.de/discussionpapers

Discussion Papers of DIW Berlin are indexed in RePEc and SSRN:

http://ideas.repec.org/s/diw/diwwpp.html

http://www.ssrn.com/link/DIW-Berlin-German-Inst-Econ-Res.html 


\title{
Political Corruption in the Execution of Public Contracts*
}

\author{
Olga Chiappinelli ${ }^{\dagger}$
}

September 6, 2016

\begin{abstract}
This paper presents a novel theory of corruption in public procurement. It considers an agency setting of contract execution where the principal is a politician who can commit to a contract auditing policy. It is found that a benevolent politician, by choosing a sufficiently strict auditing, deters the contracting firm from padding costs; conversely, a selfish politician chooses a relatively lax auditing in order to create an incentive for cost-padding, and engages in corruption with the firm in case of detection. If the cost of auditing is high enough, even a benevolent politician might prefer to allow cost-padding.
\end{abstract}

Keywords: Corruption in procurement; Cost-padding; Selfish politician; Endogenous auditing; Procurement contracts; Principal-agent model.

JEL Classification: D73; D82; L51.

*I would like to thank Andrea Vindigni, Nicola Dimitri, Elisabetta Iossa, Jing-Yuan Chiou, Shuo Liu, Claudia Cerrone, Alessandro Belmonte, Carlo Prato, Pio Baake, Malin Arve, Chiara Canta, Tina Søreide, Paola Valbonesi, Nicola Doni, Marco Pagnozzi, Giancarlo Spagnolo, Antonio Estache as well as participants at the SMYE 2015 (Ghent University), ASSET 2015 (University of Granada), EWM Econometric Society 2015 (IGIER-Bocconi), BERA Micro Workshop 2016 (DIW Berlin), "Contracts, Procurement \& PublicPrivate Arrangements 2016" (IAE Paris - Sorbonne Business School), EEA-ESEM 2016 conferences, and seminar participants at IMT Lucca and University of Siena for very useful comments and suggestions. I am grateful for financial support from the Federal Ministry for Economic Affairs and Energy (research grant SEEE, funding number 03MAP316). The usual disclaimer applies.

$\dagger$ DIW Berlin (German Institute for Economic Research). Email: ochiappinelli@diw.de. 


\section{Introduction}

In June 2014 a huge corruption scandal broke in Italy concerning the MOSE, an ambitious public project of underwater barriers designed to protect Venice from flooding. The investigations led to the arrest of 35 people including entrepreneurs, bureaucrats and politicians with the charges of fiscal fraud, corruption, extortion and money laundering. The inquiry unveiled a well-established system where contracting and sub-contracting firms in the consortium in charge of the MOSE works systematically embezzled project funds, mainly via inflated and false billing. The embezzled money was then allocated to managers' private use and to buy the favoritism of local and national-level leading politicians (e.g., to unblock extra funding to the project) and the connivance of the public officials in charge of the monitoring of the works. ${ }^{1}$ Authorities reported that the money embezzled since the beginning of the works in 2003 to the time of the inquiry, amounted to $€ 1$ billion, i.e. 20 percent of the cost of the MOSE project.

If, on one hand, the MOSE case is exceptional for its magnitude, on the other hand it is emblematic of how corruption can be a major issue in big public works projects and, generally, in public procurement. Episodes of corruption of various entity are ubiquitous in both developing and developed countries (see e.g., Rose-Ackerman (1999), Auriol (2006), OECD (2007) and Ware et al. (2007)). It is estimated that at least $€ 400$ billion a year are lost to bribery and corruption in public procurement globally. In more relative terms, this implies an increase in government purchasing costs of about 20-25\% (Transparency International (2006)). Such huge cost overruns not only severely distort public finances, but may also impair the delivery of essential public services (both in terms of delay and of suboptimal quality) and, in the context of internationally funded development projects, eventually retard efforts to reduce poverty (see e.g., Rose-Ackerman (1975), Rose-Ackerman (1999), Ware et al. (2007)). ${ }^{2}$

Given the magnitude of the phenomenon, the economics profession has in recent years increased its attention to the issue. However, it has done that in a partial way, neglecting two fundamental features of real corruption in public procurement, as highlighted by the MOSE case and many other episodes. The former concerns the timing and the latter the nature of corruption. As for the timing, most of the existing literature focused on corrup-

\footnotetext{
${ }^{1}$ Authorities reported that the consortium paid real "annual wages"- ranging from $€ 100.000$ to $€ 1$ million per person per year - to politicians (both right- and left-wing and also as electoral funding) public officials, judges, and intelligence officers. In addition to monetary "wages", substantial favors were paid in in-kind utilities (e.g., holidays, private flights). The president of the consortium, which was also nicknamed by people in the corrupt system as the "Doge" (the name formerly used for the chief magistrate and leader of the Republic of Venice), used diverted money to increase his own salary by $€ 1$ million per year, to benefit relatives and even to enhance his reputation as a philanthropist of Venice - creating job positions, funding the university, sponsoring public events and even funding for $€ 5$ million the America's Cup World Series Venice 2012 (source: Il Venerdi di Repubblica, 20 June 2014).

${ }^{2}$ Public procurement is particularly prone to corruption (relative to other major components of a country's public expenditure) because it occurs through a relatively low number of high value transactions - which makes it more attractive to potentially corrupt public officials and politicians - and features a relatively high degree of discretionary power - which creates room for corruption at each stage of the procurement process.
} 
tion occurring at the award stage of procurement; that is the case when the auctioneer, as an agent of the public purchaser, can abuse his discretion to manipulate the tender in favor of a specific participant in exchange for a bribe (see e.g. theoretical contributions by Laffont and Tirole (1991), Celentani and Ganuza (2002), Burguet and Che (2004) Compte et al. (2005), Lengwiler and Wolfstetter (2006), Burguet and Perry (2007) and empirical investigations by Di Tella and Schargrodsky (2003), and Bandiera et al. (2009)).

However, corruption may also severely affect the planning and implementation phases of procurement (see e.g. Boehm and Olaya (2006) and Ware et al. (2007)). In particular, the most severe overruns are likely to follow from corruption in the execution of procurement contracts, which can occur in many different forms (Piga (2011)). For example, the contracting firm can bribe the public official in charge of the monitoring of the works, to make him protect and hide low quality (e.g., the use of substandard materials) or "costpadding", namely accounting manipulations that allow the firm to inflate reimbursable costs and divert public money to private uses (i.e., embezzlement). Cost-padding activities include increasing expense claims for materials, supplies and services (e.g., by inflating invoices or having ghost employees and consulting studies on the project payroll), charging advertising and other unallowable expenses to project costs, and increasing managerial compensation (see e.g., Søreide (2005), Ware et al. (2007)).

Despite its practical relevance, to the best of my knowledge only two works have provided an economic analysis of post-tendering corruption in public procurement. Laffont and Tirole (1993, Ch. 12) analyzed cost-padding as a regulatory agency problem where corruption can occur between the firm and the bureaucrat who audits the firm on behalf of a benevolent regulator, finding that while corruption is always prevented in equilibrium, cost-padding can be optimal for the principal when it is too costly to deter it (in terms of information rents). More recently, Iossa and Martimort (2013) have studied how the procurement contract (and in particular the allocation of risk between parties) should be designed in order to minimize the scope for post-tender corruption, finding that the solution depends on a country's quality of auditing institutions and levels of corruption.

The second main aspect of corruption in procurement neglected in the literature is that in addition to bureaucratic corruption - i.e. the case that the firm bribes the officials in charge of the awarding of the contract or the monitoring of contract execution - political corruption can also arise. As big scandals like the MOSE show, when the potential gains from a corrupt deal are large, corruption may involve higher levels of the government hierarchy, up to top-level politicians. Bureaucratic malfeasance can be induced, guided and sustained by dishonest interests at the top of the political hierarchy. ${ }^{3}$

While the general issue that all levels of government can be rent-seeking and hence corruptible has a long-standing tradition in the "Public Choice" and political economy

\footnotetext{
${ }^{3}$ Other examples, beside the MOSE case, where corruption was found to involve top politicians include the infamous Italian "Tangentopoli" case, the more recent Italians scandals concerning the world's Fair EXPO 2015 and the awarding of waste and transport contracts in Rome ("Mafia Capitale" case) and in Lombardia; the very many cases concerning the international development projects in Africa, Latin America, India and Indonesia; and the case involving Zhou Yongkang in China. For other cases around the world see Rose-Ackerman (1999) and Ware et al. (2007).
} 
research agendas (see e.g., Buchanan and Tullock (1962), Barro (1973), Ferejohn (1986), Shleifer and Vishny (1993),Gradstein (1993), Acemoglu and Verdier (2000), Persson and Tabellini (2000), Grossman and Helpman (2002), Besley (2007)), the procurement literature has been stuck with the paradigm of corruption as an agency problem where bureaucrats are corruptible agents of benevolent governments and politicians - much in the spirit of the pioneers (see e.g., Becker and Stigler (1974), Banfield (1975), Rose-Ackerman (1975) and Klitgaard (1988)). ${ }^{4}$ This view is inconsistent with the most severe real corruption cases. To the best of my knowledge, the only exceptions to this norm are two empirical studies by Coviello and Gagliarducci (2010) and Goldman et al. (2013); in the former it is found that more time in office for politicians is associated with a worsening of procurement performance, whereas the latter finds that firms that are connected to winning parties are significantly more likely to experience an increase in procurement contracts. However, both of these papers focus on corruption at the award stage ${ }^{5}$. Dhami and Al-Nowaihi (2007) have a theoretical agency model where the principal (a politician) is partially self-interested and engage in corruption with the agent (a corruptible bureaucrat), but in the different context of provision of a public output.

The aim of the present work is to make a step toward filling the gaps identified in the literature. My contribution is to provide a theoretical framework to investigate the occurrence of cost-padding in the execution of public contracts as a problem of political corruption. Namely, I ask whether it can be the case that the politician at the top of the procurement hierarchy can be selfish and interested in obtaining a share of the money embezzled by the firm, and, if this is the case, whether and how he is responsible himself for inducing the firm to embezzle money.

To explore this possibility, I build on the agency regulatory model of cost-padding in Laffont and Tirole (1993), to allow for the principal to be a partially selfish politician who cares not only about social welfare but also about his private utility, and to be the main responsible not only for the design of procurement contracts but also for the contract auditing policy. As an imperfectly informed principal, the politician is not able to observe whether the firm embezzles funds. However, after contract execution he is able to audit the firm and detect cost-padding with some probability. Upon detection the politician can then decide whether to punish the firm by confiscating and returning embezzled funds to consumers, or rather enter a corrupt transaction with the firm, that is to suppress evidence of cost-padding in exchange of a share of the embezzled money. The auditing policy, which determines the probability of detection, is endogenous in the model and strategically chosen by the politician. Since the incentives for the firm to pad costs in the first place will be influenced by the announced auditing policy, the politician is able to manipulate the incentive for the firm through the auditing choice, and induce or prevent embezzlement according to his own motives.

The main result of the paper reflects exactly this intuition and is that a benevolent politician - provided the cost of auditing is sufficiently low - chooses a relatively strict

\footnotetext{
${ }^{4}$ See Aidt (2003) for a survey on economic models of corruption.

${ }^{5}$ Also see Golden and Picci (2005). For other empirical studies on (mainly bureaucratic) corruption in procurement see Guasch and Straub (2009) Di Tella and Schargrodsky (2003) Bandiera et al. (2009).
} 
auditing policy, thereby preventing the firm from engaging in cost-padding; conversely, a sufficiently selfish politician, by choosing a relatively lax auditing policy, creates an incentive for embezzlement in optimal contracts and, in case of detection, enters in a corrupt transaction with the firm. If the cost of auditing is too high, even a benevolent politician might prefer to allow for cost-padding and save on the cost of auditing in order to minimize the welfare loss. This result is consistent with the "mixed" nature of the politician, who cares both about social welfare and his private utility. Since cost-padding implies a higher cost for consumers in terms of distortionary taxation, only a politician who is selfish enough, that is who give sufficiently higher weight to his private utility than to social welfare, is willing to allow for cost-padding to occur.

Interestingly, the two types of politicians face two different trade-offs when choosing the optimal level of auditing. A selfish politician, who does not care about taxpayers bearing higher project and auditing costs, would in principle prefer high auditing, which leads to higher detection, hence increasing his probability to get a bribe; at the same time however, high auditing reduces the firm's incentive to engage in cost-padding, which reduces his expected bribe. Therefore, a selfish politician optimally chooses the highest possible auditing level that is consistent with the firm having an incentive to pad costs. On the other hand, a benevolent politician, who cares about welfare consequences of higher project and auditing cost, would prefer higher auditing in order to prevent cost-padding, but also takes into account that higher auditing implies higher auditing costs. Therefore, he optimally chooses the lowest possible auditing level that still deters the firm from padding costs, unless the cost of auditing is too high, in which case he completely forgoes cost-padding prevention.

An interesting comparative statics result which emerges is that an improvement in the efficiency of the fiscal system makes cost-padding easier to occur. This happens since a decrease in the social cost of cost-padding (in terms of less distortionary taxation) also induces less selfish politicians to engage in corruption. Therefore, since politicians induce cost-padding by reducing auditing, the model also predicts endogenous substitutability between the level of auditing and the efficiency of the State. This result can be interpreted in light of the debate on State capacity (Besley and Persson (2010), Acemoglu (2010), Acemoglu et al. (2011)): by increasing the stakes from staying in power, a more efficient fiscal system increases the politician's incentive to misuse public office. Therefore, without a coincident increase in political accountability, an increase in State capacity can be detrimental.

A possibility suggested by my results is that the law should provide for the auditing of contract execution to be responsibility of an external independent authority rather than of the purchasing authority. Under the current legislation (e.g., Directives 2004/17/EC, $2004 / 18 / \mathrm{EC}$ for the EU), the bureaucrat that in practice is responsible for contract monitoring is an employee of the purchasing authority. The same is true for the bureaucrats in charge of contract design and contract award. In this legislative context, corrupt higher level politicians are able to influence employment decisions down along the authority hierarchy, and place complicit officials induce malfeasance and guarantee their own participation in corrupt deals (OECD (2006)). 
If, on the other hand, the law provided for the monitoring of contract execution to be responsibility of an external independent authority (possibly combined with random forensic audits), it would be much more difficult for the politician to exert his influence (see e.g., Ware et al. (2007)). Also, in order to reduce the interference of politicians in contract design and award activities, a higher degree of centralization and aggregation of procurement may help, for example enhancing the role of regional or national procurement agencies (see e.g., Dimitri et al. (2006) and references therein). Again, it would be much harder for the politician to influence a larger and independent authority. Finally, standardized contracting may also prove useful in this sense (see e.g., Iossa and Martimort (2014)).

The rest of the paper is structured as follows: Section 2 presents the model; Section 3 analyzes the corrupt bargaining between the politician and the firm; Section 4 characterizes the politician's optimal choice of procurement contracts; Section 5 analyzes his optimal choice of the auditing policy; Section 6 concludes. All proofs are gathered in the Appendix.

\section{The model}

\section{$2.1 \quad$ Setting}

A politician (principal) wants to contract the realization of a single and indivisible project of public utility from a construction firm (agent). ${ }^{6}$ The basic agency setting is the same as in the cost-padding model of Laffont and Tirole (1993, Ch. 12) (LT in the following).

The firm's technology is represented by a linear cost function

$$
C(\beta, e, a)=\beta-e+a
$$

where $\beta$ is a parameter that measures the technological efficiency (or "intrinsic productivity") of the firm, with $\beta \in\left\{\beta_{L}, \beta_{H}\right\}, \beta_{L}<\beta_{H}$ ( $\beta_{H}$ corresponds to a less efficient technology), $e$ is the level of cost-reducing effort exerted by the firm $\left(C_{e}<0\right)$ and $a$ is its level of cost-padding activity, i.e. embezzlement of public funds $\left(C_{a}>0\right)$. The realized project cost $C$ is, therefore, equal to actual cost $(\beta-e)$ plus embezzlement $a$.

The efficiency parameter $\beta$ is private information to the firm. The politician only has a prior distribution over the two types i.e., $\nu=P\left(\beta=\beta_{L}\right) \in(0,1)$. Moreover, cost-reducing effort $e$ and cost-padding activity $a$ are both unobservable by the politician. He is only able to observe (and verify) realized cost $C$, without disentangling its determinants; that is, if he observes a relatively high cost is not able to tell whether this is due to the fact that the firm's technology is inefficient, or because the manager is lazy (he is putting in a suboptimal level of effort) or because he is stealing project funds. Therefore, this setting is an extension of the standard regulatory agency problem (see e.g., Laffont and Tirole (1986)) where moral hazard becomes two-dimensional: the firm can try to inflate observed costs (and hence the reimbursement it receives from the regulator) not only by exerting a

\footnotetext{
${ }^{6}$ The firm might be the winner of a procurement tender or a concessionaire for that project (like in the MOSE case).
} 
suboptimal level of effort, but also by embezzling public money. ${ }^{7}$

The politician reimburses the realized $\operatorname{cost} C$ and pays to the firm a net monetary transfer $t(C) \geq 0$ (the firm has limited-liability). ${ }^{8}$ A contract between the politician and the firm specifies a pair $(t, C)$. If the firm does not accept the contract, it gets its reservation utility, which is normalized to zero. ${ }^{9}$

The firm bears an increasing and convex disutility of effort (expressed in monetary terms) $\psi(e), \psi_{e}>0, \psi_{e e}>0 .{ }^{10}$ Notice that this has an important implication, insofar when the firm commits to a contractual cost level, the higher the level of embezzlement it wants to achieve, the higher effort it needs to exert (given $C$ and $\beta$, an increase in $a$ needs to counterbalanced by an equivalent increase in $e$ ). Therefore, the firm has a cost from cost-padding in terms of extra disutility of effort. The focus of this model is on costpadding, so that the relevant choice variable for the firm will be cost-padding, while its level of effort will be determined residually. For simplicity it is assumed that equilibrium effort is always positive.

The politician will offer a menu of contracts that maximize his objective function. Differently from LT and from standard contract theoretical analysis of regulation and procurement, the principal is not a purely benevolent social welfare maximizer, but is partially selfish, that is he maximizes a weighted average between social welfare $(S W)$ and some measure of private utility $(P U)$, which will be both defined shortly. Therefore, his objective function has the form:

$$
U=S W+\mu P U
$$

where $\mu \in[0, \infty)$ is a selfishness parameter measuring the weight placed on private utility relative to social welfare (see e.g., Grossman and Helpman (1994), Dittmann (2006), Dhami and Al-Nowaihi (2007)). ${ }^{11}$

According to the value of $\mu$, politicians can be categorized as follows:

Definition 1. If $\mu>1$ the politician is "relatively selfish", i.e., he cares more about his private utility; if $\mu \leq 1$ the politician is "relatively benevolent", i.e., he cares more about social welfare.

The "Contract Theory" purely benevolent politician and the "Public Choice" purely selfish politician are limit cases of this modelization, where, respectively, $\mu=0$ and $\mu \rightarrow \infty$.

\footnotetext{
${ }^{7}$ Other cost-padding models that build on Laffont and Tirole (1986) include Chu and Sappington (2007) and Bougheas and Worrall (2012). However, these models do not introduce a second moral-hazard variable, arguing that cost-padding can be simply interpreted as negative effort. Additionally, neither of these models include auditing or corruption.

${ }^{8}$ Typically, $t=q-r C$, where $q$ is a fixed fee and $r$ represents the fraction of costs born by the firm (i.e., the so called incentive power of the contract).

${ }^{9}$ It is assumed that for the politician it is worth realizing the project even with an inefficient firm $\left(\beta=\beta_{H}\right)$.

${ }^{10}$ The following regularity conditions also hold: $\psi(0)=0$ and $\lim _{e \rightarrow \beta} \psi(e)=+\infty$.

${ }^{11}$ The objective function in (2) identifies the politician as a top politician rather than a bureaucrat. A bureaucrat would have different motives, mostly driven by private career concerns (see e.g., Alesina and Tabellini (2007) and Alesina and Tabellini (2008)).
} 
The type of the politician is known to the firm.

The project has constant value $S>0$ for consumers. To finance project cost the politician levies distortionary taxation, namely, for each dollar of taxes consumers bear disutility $\$(1+\lambda)$, where $\lambda>0$ denotes the shadow cost of public funds. This implies that when firm pad costs, consumers, as taxpayers, bear an extra cost in terms of distortionary taxation.

Finally, it is assumed that all players (i.e., politician, firm and consumers) are riskneutral, and that there is an implicit mechanism that makes all contracts and side-contracts enforceable and non-renegotiable.

\subsection{Auditing of contract execution and corruption}

The politician chooses and announces an auditing policy before offering contracts to the firm. ${ }^{12}$ After implementing the contract, i.e., choosing the level of cost-padding (and, residually, the level of effort), the firm undergoes auditing.

Differently from LT, I do not introduce a third independent tier in the auditing structure (i.e., a supervisor), interpreting that the material executor is some ghost bureaucrat whose motives are in line with those of the politician, like a "blind executor". Therefore, the model neglects the agency relationship between the politician and the bureaucrat, implicitly assuming that the politician has full control and observability of the bureaucrat's behavior. In practice, the bureaucrat in charge of auditing contract execution is an employee of the contracting authority. The "blind executor" assumption therefore amounts to the possibility that the top politician has an influence over the employment decisions in the contracting authority, which often happens in real cases. ${ }^{13}$

The auditing policy simply amounts to a level of detection probability $\rho \in(0,1)$, a low probability being interpreted as a lax policy (or weak auditing technology) and a high probability as a strict policy (or strong auditing technology). Moreover, the auditing technology has an increasing linear $\operatorname{cost} \mathcal{C}(\rho)=c \rho(c>0)$, which is also covered out of taxation. The auditing produces hard-information, namely for a given level of cost-padding $a \geq 0$, the auditing detects the true (and verifiable) level of cost-padding ( $\hat{a}=a)$ with probability $\rho$ and nothing $(\hat{a}=\emptyset)$ with probability $1-\rho .^{14}$

If no hard evidence of cost-padding is found, the firm keeps the entire amount of diverted money; if instead hard evidence is found, the politician has two possible choices: either he confiscates the money and returns it to consumers as a lump-sum transfer, or he

\footnotetext{
${ }^{12}$ Some models in the law enforcement and economics of crime research agendas also endogenize the detection policy (see e.g., Polinsky and Shavell (2001) and Dittmann (2006)).

${ }^{13}$ For example, this was reported to occur in the MOSE case and in the other episodes mentioned in footnote 3. Dhami and Al-Nowaihi (2007) also have a two-tier auditing structure where the principal (a politician) can be partially self-interested and audit himself the agent (a corruptible bureaucrat). However the auditing technology is exogenous in their case. For three-tier models of auditing and regulation see e.g., Tirole (1992), Laffont and Tirole (1993), Mookherjee and Png (1995), Khalil and Lawarrée (1995) and Kofman and Lawarrée (1996).

${ }^{14} \mathrm{LT}$ instead assume a soft-information auditing technology i.e., the signals of the true level of costpadding are always imperfect and errors can occur.
} 
enters a corrupt transaction with the firm where he suppresses evidence if the firm agrees to share the embezzled money. ${ }^{15}$ If the firm agrees with the sharing, the politician and the firm divide the money and nothing is returned to consumers. If instead the firm does not agree with the sharing, the amount of embezzled money is confiscated and returned back to consumers.

It is argued that the politician does not keep all the money for himself in case of disagreement because he fears that the firm may report something to the authorities, while he is safe if he returns money back to consumers. The role of judicial authorities, as implicitly assumed in the model, is passive and marginal: they do not actively investigate on possible collusion between the firm and the politician, but merely receive the firm's accusation against the politician. Hence, the politician tries to pocket money only in the case that an agreement with the firm is reached. ${ }^{16}$

The corrupt sharing is determined by the Nash-bargaining solution (see e.g. Dhami and Al-Nowaihi (2007).) I believe that this is the appropriate modelization in this context, since what I have in mind is the world of big projects where the gains from cost-padding are potentially large and contractors and politicians are likely to have even bargaining powers. ${ }^{17}$ Importantly, the stakes of corruption, which amount to the level of money embezzled by firm, are endogenous in this model and depend on the politician's behavior.

The auditing choice is assumed to be credible and binding, implying that after contract implementation the blind executor will simply audit the firm according to the predetermined auditing policy. In practice, a possibility for the politician to credibly commit to an auditing policy is through the choice of the auditing executor: to commit to a strict auditing policy he can choose a bureaucrat who has a reputation (known to the firm) of being strict and virtuous, while to commit to a lax auditing policy he can choose a bureaucrat with a bad reputation.

The timing of the game is summarized as follows:

1) Nature chooses the state of efficiency $\beta$;

2) The politician announces and commits to an auditing policy $\rho$;

3) The politician offers a contract to the firm specifying a transfer-cost pair $(t, C)$;

4) The politician and the firm sign the contract. The firm chooses cost-padding level $a$ and realizes the project at contracted $\operatorname{cost} C$ (exerted effort $e$ is determined residually);

5) The firm undergoes auditing and the politician discovers evidence of cost-padding with

\footnotetext{
${ }^{15}$ Different from LT, it is assumed that the money diverted by cost-padding can be fully recouped by the politician in case of detection, whereas LT assume that cost-padding is fully consumed by the firm before the audit.

${ }^{16} \mathrm{~A}$ possible alternative timing would be that the collusive bargaining and agreement between the politician and the firm occurs at the initial contracting stage. However, as long as contracts and side contracts are assumed to be non-renegotiable this timing issues should not have any bite in the model.

${ }^{17}$ Note that Nash bargaining is sustained by the assumption of enforceability and non-renegotiability of side-contracts. Otherwise, the politician may ex-post renegotiate the side-contract and make a more favorable (to him) take-it-or-leave-it offer to the firm, and any firm's threat of reporting in case the politician offers a lower share than the one specified by the Nash-bargaining outcome would not be credible (since the firm is worse off by reporting to the authorities). Only were the politician keep the entire amount of embezzled money would the firm have a credible incentive to report.
} 
probability $\rho$;

6) Upon detection, the politician decides whether to sign a corrupt side-contract with the firm to share embezzled money, or to return money to consumers; and

7) Transfers are realized.

The politician is the residual claimant of the vertical structure. He designs the policy instruments at his disposal, i.e., the auditing policy and the procurement contracts, with the objective of maximizing his objective function. Notice that given his mixed motives, the equilibrium choices of the politician will typically differ from the social-welfare maximizing ones.

\subsection{Payoffs}

On the basis of the setting described above, it is now possible to define the payoff functions of the firm and the politician.

\subsubsection{Firm}

The profit of a firm of type $\beta$ who accepts contract $(t, C)$ and engages in a level of costpadding $a \geq 0$ is:

$$
\Pi= \begin{cases}t+a-\psi(\beta-C+a), & \text { if } \hat{a}=\emptyset \\ t+a^{F}-\psi(\beta-C+a), & \text { if } \hat{a}=a\end{cases}
$$

That is, in case hard evidence of cost-padding is not found $(\hat{a}=\emptyset)$ the firm keeps the full amount of embezzled money $a$. If instead hard evidence of cost-padding is found $(\hat{a}=a)$, the share of embezzled money accruing to the firm, $a^{F}$, depends on whether the politician is willing to enter Nash-bargaining with the firm, which will be determined endogenously. Notice that $a$ represents both the level of cost-padding chosen by the firm and the amount of embezzled money; thus, it also amounts to the endogenous stakes of corruption. Additionally, the transfer $t$ paid by the politician is not dependent on the outcome of the auditing. The firm is only punished with the confiscation of the diverted money. ${ }^{18}$ Regardless, the firm bears disutility $\psi(\beta-C+a)$ from exerting the level of effort needed to afford some embezzlement $a$ after committing to cost level $C$. The expected profit of the firm can therefore be written as:

$$
\mathbb{E}[\Pi]=t+\mathbb{E}\left[a^{F}\right]-\psi(\beta-C+a)
$$

where $0 \leq \mathbb{E}\left[a^{F}\right] \leq a$.

\subsubsection{Politician}

In this model the private utility of the politician merely amounts to the share of embezzled money accruing to the politician, $a^{P}$. Therefore, the objective function of a politician with

\footnotetext{
${ }^{18}$ While in LT the penalty in case of detection is the retention of transfer $\left(t_{a}=0\right)$.
} 
self interest $\mu$ when the contracting firm is of type $\beta$, accepts contract $(t, C)$ and engages in cost-padding level $a \geq 0$ is:

$$
\mathbb{E}[U]=\mathbb{E}[S W]+\mu \mathbb{E}\left[a^{P}\right]
$$

Now I turn to defining social welfare $S W$ in this model. Differently from some authors in the literature (see e.g., Dhami and Al-Nowaihi (2007), Garoupa and Klerman (2002)), who argue that including profits in social welfare is questionable because of the inclusion of the proceeds of corruption (and so they adopt consumer surplus as the measure of social welfare), I rather believe that the utilitarian view, as adopted by LT, is more realistic, insofar real world regulators need to take into account the interest of the private sector, even if it may engage in illegal activities. However, I go a step further. Since the preferences of the politician are such that he is benevolent relative to the social welfare component, I assume that conditional upon detection, the politician will, regardless of his type, only include in social welfare the "socially efficient" level of profits, $\Pi_{S W}$, i.e., profits net of the firm's gain from cost-padding (which after detection is observable and measurable). ${ }^{19}$ More formally,

Assumption 1. If $\hat{a}=a, \Pi_{S W} \equiv t-\psi(\beta-C+a)$.

Accordingly, I will distinguish between the expected profit of the firm $\mathbb{E}[\Pi]$, which was defined in (4) and, using Assumption 1, can be written as

$$
\mathbb{E}[\Pi]=\Pi_{S W}+\mathbb{E}\left[a^{F}\right]
$$

and the part of expected profit to be included in social welfare,

$$
\mathbb{E}\left[\Pi_{S W}\right]=\Pi_{S W}+\mathbb{E}\left[a_{S W}^{F}\right]
$$

where $\mathbb{E}\left[a_{S W}^{F}\right]=(1-\rho) a$, with $\mathbb{E}\left[a_{S W}^{F}\right] \leq \mathbb{E}\left[a^{F}\right]$.

On the other hand the expected welfare of consumers when the contracting firm is of type $\beta$, accepts contract $(t, C)$ and engages in cost-padding level $a \geq 0$ is:

$$
\mathbb{E}[W]=S+\mathbb{E}\left[a^{C}\right]-(1+\lambda)(C+t+c \rho)
$$

where $\mathbb{E}\left[a^{C}\right]$ is the expected amount of embezzled money that will be returned back to the consumers as a lump-sum transfer. Notice that since both the extra project cost due to cost-padding and the cost of auditing will be covered out of taxation, the tax burden for consumers increases not only in the level of embezzlement but also in the level of auditing.

Therefore, the politician's objective function can be written as:

$$
\mathbb{E}[U]=\mathbb{E}[W]+\mathbb{E}\left[\Pi_{S W}\right]+\mu \mathbb{E}\left[a^{P}\right]
$$

Or, extensively:

$$
\mathbb{E}[U]=S+\mathbb{E}\left[a^{C}\right]-(1+\lambda)(C+t+c \rho)+t+\mathbb{E}\left[a_{S W}^{F}\right]-\psi(\beta-C+a)+\mu \mathbb{E}\left[a^{P}\right]
$$

\footnotetext{
${ }^{19}$ The increased disutility in effort remains the same since effort has already been exerted.
} 


\subsection{Strategies and equilibrium concept}

A strategy for the politician specifies an auditing policy (i.e., detection probability) $\rho$, a procurement contract $(t, C)$ and an entrance decision $E D$ about whether entering into corrupt bargaining with the firm upon detection of cost-padding; formally, $s_{P}=\{\rho ;((t, C)) ;(E D)\}$ with $E D \in\{$ enter, not enter $\}{ }^{20}$ A strategy for (each type of) the firm specifies a contract decision $C D$ about whether accepting or rejecting the contract offer, a level of costpadding $a$, and an entrance decision $E D$ about whether entering into corrupt bargaining with the politician upon detection; formally $s_{F}\left(\beta_{i}\right)=\{(C D) ;(a) ;(E D)\}$, with $i \in\{L, H\}$, $C D \in\{$ accept, reject $\}, E D \in\{$ enter, not enter $\}$.

The relevant equilibrium concept is Perfect Bayesian Equilibrium (PBE), since the politician chooses his strategy under incomplete information about the type of the firm he is facing. Notice that while the politician will update his beliefs after contract execution (since the firm may reveal some information about its type through the contract choice), however he will not use this information in the auditing subgame, since it is assumed that he can credibly commit to the announced auditing policy (the blind executor will simply audit the firm according to the announced auditing policy). ${ }^{21}$ Also, notice that a successful audit does not add any new information about the firm's type that has not already been revealed by the firm's contract choice.

A PBE in this context is a pair $(S, B)$ - consisting of a strategy profile $S=\left(s_{P}, s_{F}\left(\beta_{i}\right)\right)$ and a belief system (i.e., a probability distribution on $\left\{\beta_{H}, \beta_{L}\right\}$ for the politician after histories where he has the move, namely after Nature's move (i.e., after empty history $\emptyset)$ and after the firm's contractual decision (i.e., after infinite histories $(\rho,(t, C), C D))$ ) $B=\left(b(\emptyset)\left(\beta_{i}\right), b((\rho,(t, C), C D))\left(\beta_{i}\right)\right)$ - which satisfy sequential rationality, correct initial beliefs, action-determined beliefs and Bayesian updating (see Definition 232.1 in Osborne and Rubinstein (1994)).

I solve the game by backward induction, looking for the complete set of PBE. Therefore I will first characterize the equilibrium of the corrupt bargaining between the firm and politician, and derive the equilibrium expected shares of embezzled money $\mathbb{E}\left[a^{F *}\right], \mathbb{E}\left[a^{P *}\right]$ and $\mathbb{E}\left[a^{C *}\right]$; then, on the basis of continuation payoffs I will derive the optimal procurement contracts for the politician $\left(t^{*}, C^{*}\right)$ (which, since the politician as usual acts as a Stackelberg leader, takes into account the firm's optimal choice of cost-padding); last, on the basis of optimal contracts, I will analyze the optimal choice of detection probability for the politician, $\rho^{*}$. Notice that until the last stage (Section 5), the detection probability is considered as a parameter, $\rho \in(0,1)$.

\footnotetext{
${ }^{20}$ Where $(t, C)$ and $(E D)$ are tuples each component of which is the action that the politician has to play after each possible relevant history (e.g., each element of $(t, C)$ specifies the contract that the politician needs to offer after a given choice of detection probability).

${ }^{21} \mathrm{My}$ conjecture is that nothing substantial would change in equilibrium if he had the possibility to change the level of auditing, at least as long as auditing is costless. I will return to this in Section 6.
} 


\section{Corrupt bargaining solution}

If hard evidence of cost-padding is not found $(\hat{a}=\emptyset)$, the equilibrium shares of embezzled money are trivially $a^{F *}=a, a^{P *}=0$ and $a^{C *}=0$. Instead, if hard evidence of costpadding is found $(\hat{a}=a)$, the politician chooses the most profitable between the two options of entering Nash-bargaining with the firm or returning money to consumers. This decision depends on the Nash-bargaining solution, which is now derived.

Let $a^{P} \in[0, a]$ be the politician's share of the embezzled money. If the politician and the firm manage to reach an agreement on the sharing of the "cake", their respective payoffs are: ${ }^{22}$

$$
\begin{gathered}
U_{A}=S-(1+\lambda)(C+t+c \rho)+\Pi_{S W}+\mu a^{P} \\
\Pi_{A}=\Pi_{S W}+\left(a-a^{P}\right)
\end{gathered}
$$

If instead they do not manage to reach an agreement, the politician returns money to consumers as a lump-sum transfer. Therefore, the disagreement payoffs are:

$$
\begin{gathered}
U_{D}=S+a-(1+\lambda)(C+t+c \rho)+\Pi_{S W} \\
\Pi_{D}=\Pi_{S W}
\end{gathered}
$$

The equilibrium shares will be given by the solution to the following problem:

$$
\max _{a^{P}:\left(U_{A}, \Pi_{A}\right) \geq\left(U_{D}, \Pi_{D}\right)}\left(U_{A}-U_{D}\right)\left(\Pi_{A}-\Pi_{D}\right)
$$

which is

$$
a^{P *}=\frac{\mu+1}{2 \mu} a, \quad a^{F *}=\frac{\mu-1}{2 \mu} a
$$

It is immediate to check that $U_{A} \geq U_{D}$ holds only if the politician is relatively selfish $(\mu>1)$ (while the firm always finds it profitable to enter bargaining). As expected, only a selfish enough politician enters corrupt Nash Bargaining. Otherwise $(\mu \leq 1)$, he returns money to consumers. Importantly, notice that the politician does not need to be fully benevolent $(\mu=0)$ to decide not to enter the corrupt deal. This is an interesting aspect of the result, since it allows for the realistic interpretation that politicians can well be selfish, but only particularly selfish ones - the ones who let private cause substantially exceed public interest - will damage the public by engaging in corruption.

Therefore, if the politician is relatively selfish (indicated with subscript $S$ ) the optimal

\footnotetext{
${ }^{22}$ Notice that without Assumption 1 there would be a problem in implementing Nash-bargaining, since the utility of one bargaining party- the politician - would have included the utility of the other bargaining party - the firm. The interpretation of Assumption 1 is that the politician temporarily confiscates the money and invites the firm to Nash-bargain over it.
} 
shares of embezzled money are: $a_{S}^{P *}=\frac{\mu+1}{2 \mu} a, a_{S}^{F *}=\frac{\mu-1}{2 \mu} a, a_{S}^{C *}=0$. Notice that $\frac{\partial a_{S}^{P *}}{\partial \mu}<0$ (with $\lim _{\mu \rightarrow \infty} \frac{\mu+1}{2 \mu} a=\frac{a}{2}, \lim _{\mu \rightarrow 1+} \frac{\mu+1}{2 \mu} a=a$ ). Interpretation is that a more eager politician is easier to bribe: like impatience, selfishness reduces bargaining power. Instead, if the politician is relatively benevolent (indicated with subscript $B$ ) the optimal shares are: $a_{B}^{P *}=0, a_{B}^{F *}=0, a_{B}^{C *}=a .^{23}$

From the results above it is possible to derive the optimal expected shares of embezzled money and state the following result:

Proposition 1. (Expected equilibrium shares of embezzled money) The expected equilibrium shares of embezzled money depend on the selfishness of the politician and are as follows:

$$
\mathbb{E}\left[a_{j}^{P *}\right]=\left\{\begin{array}{ll}
0, & j=B \\
\rho \frac{\mu+1}{2 \mu} a, & j=S
\end{array}, \mathbb{E}\left[a_{j}^{F *}\right]=\left\{\begin{array}{ll}
(1-\rho) a, & j=B \\
\left(1-\rho \frac{\mu+1}{2 \mu}\right) a, & j=S
\end{array}, \mathbb{E}\left[a_{j}^{C *}\right]= \begin{cases}\rho a, & j=B \\
0, & j=S\end{cases}\right.\right.
$$

The expected continuation payoffs for the politician and the firm from the auditing subgame are simply the expressions in (5) and (6) where money shares are at their equilibrium levels i.e.,

$$
\mathbb{E}\left[U_{j}^{*}\right]=\mathbb{E}\left[S W_{j}^{*}\right]+\mu \mathbb{E}\left[a_{j}^{P *}\right], \quad \mathbb{E}\left[\Pi_{j}^{*}\right]=\Pi_{S W}+\mathbb{E}\left[a_{j}^{F *}\right] \quad j \in\{B, S\}
$$

Notice that so far only the optimal shares of embezzled money have been determined. The optimal level of cost-padding is a decision of the firm, as addressed next.

\section{Optimal procurement contracts}

After accepting contract $(t, C)$ the firm decides its optimal level of cost-padding $a$ by solving the problem

$$
\max _{\{a \geq 0\}} \mathbb{E}\left[\Pi_{j}^{*}\right]=t+\mathbb{E}\left[a_{j}^{F *}\right]-\psi(\beta-C+a) \quad j \in\{B, S\}
$$

First, notice that since $\frac{\partial \mathbb{E}\left[a_{j}^{F *}\right]}{\partial \rho}<0$, the incentive for the firm to embezzle money is a decreasing function of the strength of auditing, as it is intuitive. Second, the fact that for a given $C$ more cost-padding needs to be financed out of more effort, combined with the fact that the marginal disutility of effort is lower for the efficient type $\left(\psi_{e \beta}>0\right)$, suggests that for a given cost level a more efficient type will engage in more cost-padding than a less efficient type. ${ }^{24}$ This result is proved to be true in LT and is stated here as follows:

Lemma 1. (Proposition $12.1 \mathrm{LT})$ If for a given cost level $C a_{L}^{*}$ and $a_{H}^{*}$ are the optimal levels of cost-padding for, respectively, $\beta_{L}$ and $\beta_{H}$, then it must be the case that $a_{L}^{*} \geq a_{H}^{*}$.

\footnotetext{
${ }^{23}$ Notice that there is a discontinuity at $\mu=1: \lim _{\mu \rightarrow 1+} a^{P *}=a$ but for $\mu \leq 1 a^{P *}=0$.

${ }^{24}$ Condition $\psi_{e \beta}>0$ amounts to the Spence-Mirrlees Single-crossing condition, which will ensure the sustainability of a separating equilibrium in optimal contracts (see e.g., Bolton and Dewatripont (2005)). Notice that $\psi_{\beta}>0$ also holds, namely the efficient type has a lower disutility from effort.
} 
It is important to remark that Lemma 1 asserts that the more efficient type engages in more cost-padding than the less efficient type for a given cost level, not that the more efficient type will engage in more cost padding in equilibrium, since in general different types will produce at different costs. The firm's optimal cost-padding choice will be a constraint in the politician's optimal contracting problem.

Notice that despite both adverse selection and moral-hazard are present in the model, the observability of costs implies a "false moral hazard setting" that collapses to a simple adverse selection problem. Therefore, the contracting problem under analysis is technically one of screening, as common in agency models of regulation (see e.g., Laffont and Tirole (1993), Laffont and Tirole (2002)).

From the Revelation Principle it is known that in this case the principal optimally offers the menu of type-contingent contracts $\left(t_{i}, C_{i}\right)$ that maximize his expected payoff function

$$
\mathbb{E}\left[U_{j}^{*}\right]=\mathbf{E}\left\{\mathbb{E}\left[S W_{j}^{*}\right]+\mu \mathbb{E}\left[a_{j}^{P *}\right]\right\}
$$

under constraints of Individual Rationality $\left(I R_{i}\right)$ and Incentive Compatibility $\left(I C_{i}\right)$, with $i \in\{L, H\}, j \in\{B, S\} .^{25}$

However, differently from the standard screening problem, here $I C_{i}$ are more problematic to characterize, since it is not known which level of cost-padding will a given type choose when mimicking the other type, so that the rents from mimicking are undetermined.

In order to derive optimal contracts, I will follow LT in focusing on the simple case where cost-padding can take only two levels $a \in\{0, \alpha\}(\alpha>0)$ and consider different possible solutions. Then I will check for which conditions on the detection probability $\rho$ can each of these optima arise in equilibrium.

Given that the cost-padding decision is stylized to a binary choice, the maximization problem for the firm stated in (18) reduces to the following: after accepting contract $(t, C)$, the firm engages in cost-padding (i.e., $a=\alpha)$ if and only if $\mathbb{E}\left[\Pi_{j}^{*}(a=\alpha)\right] \geq \mathbb{E}\left[\Pi_{j}^{*}(a=0)\right]$, or

$$
\mathbb{E}\left[\alpha_{j}^{F *}\right] \geq \psi(\beta-C+\alpha)-\psi(\beta-C)
$$

that is, if and only if the gain from engaging in cost-padding (i.e., the firm's expected share of embezzled money) outweighs its cost (i.e., the extra disutility of effort due to cost-padding). ${ }^{26}$

Moreover, the following holds:

Lemma 2. In each type of optimum, the efficient type is always required to exert the first-best level of effort, $e_{L}^{*}=e^{F B}$.

Lemma 2 is due to the fact that the politician is affected by incomplete information only trough the rent to be given to the efficient type, which depends on the effort of

\footnotetext{
${ }^{25}$ The $\mathbf{E}$ operator accounts for the uncertainty over the firm's type.

${ }^{26}$ In the following optimal contract analysis the subgame equilibrium shares of embezzled money $\mathbb{E}\left[\alpha_{j}^{F *}\right]$, $\mathbb{E}\left[\alpha_{j}^{P *}\right], \mathbb{E}\left[\alpha_{j}^{C *}\right]$ will be kept in their generic notation, and will be made explicit only when needed. Also, the star superscript will be omitted.
} 
the inefficient type. The optimal effort required from the efficient type is therefore never distorted from its first-best level.

Depending on which are the optimal levels of cost-padding for each type of firm, in principle four types of optima are possible:

Type 1 Cost-padding by the inefficient type only: $a_{H}^{*}=\alpha, a_{L}^{*}=0$;

Type 2 Cost-padding by the efficient type only: $a_{H}^{*}=0, a_{L}^{*}=\alpha$;

Type 3 Cost-padding by both types: $a_{H}^{*}=\alpha, a_{L}^{*}=\alpha$;

Type 4 No cost-padding: $a_{H}^{*}=0, a_{L}^{*}=0$.

Suppose the case $a_{H}^{*}=\alpha, a_{L}^{*}=0$ is an optimum. The cost level of the inefficient type is then $C_{H}=\beta_{H}-e_{H}+\alpha$. Let $a_{L}^{m}$ be the optimal level of cost-padding for the efficient type when it mimics the inefficient type (i.e., chooses contract $\left(C_{H}, t_{H}\right)$ ). It is known from Lemma 1 that $a_{L}^{m}=\alpha{ }^{27}$ Therefore, relevant constraints $I C_{L}$ and $I R_{H}$ are respectively:

$$
\begin{gathered}
\mathbb{E}\left[\Pi_{L}\right]=t_{L}-\psi\left(\beta_{L}-C_{L}\right) \geq t_{H}+\mathbb{E}\left[\alpha_{j}^{F}\right]-\psi\left(\beta_{L}-C_{H}+\alpha\right) \\
\mathbb{E}\left[\Pi_{H}\right]=t_{H}+\mathbb{E}\left[\alpha_{j}^{F}\right]-\psi\left(\beta_{H}-C_{H}+\alpha\right) \geq 0
\end{gathered}
$$

Using Lemma 2 and the fact the constraints above will be binding at the optimum, which implies that $\mathbb{E}\left[\Pi_{H}\right]=0$ and $\mathbb{E}\left[\Pi_{L}\right]=\Phi\left(e_{H}\right)$, where $\Phi(e)=\psi(e)-\psi(e-\Delta \beta)$ $\left(\Phi^{\prime}>0, \Delta \beta=\beta_{H}-\beta_{L}\right)$, the maximization problem of politician $j$ can be reduced to the following unconstrained problem in $e_{H}$ :

$$
\begin{aligned}
& \max _{e_{H}}\left\{\nu\left[S-(1+\lambda)\left[\beta_{L}-e^{F B}+\psi\left(e^{F B}\right)\right]-\lambda \Phi\left(e_{H}\right)\right]+(1-\nu)\left[S-(1+\lambda)\left[\beta_{H}-e_{H}+\psi\left(e_{H}\right)\right]+\right.\right. \\
& \left.(1-\nu) G_{j}\left(\alpha, \rho_{j}\right)-(1+\lambda) c \rho_{j}\right\}
\end{aligned}
$$

where $(1-\nu) G_{j}\left(\alpha, \rho_{j}\right)-(1+\lambda) c \rho_{j}$, with

$$
G_{j}\left(\alpha, \rho_{j}\right)=\mathbb{E}\left[\alpha_{j}^{C}\right]-\lambda \mathbb{E}\left[\alpha_{j}^{F}\right]-(1+\lambda) \alpha+\mathbb{E}\left[a_{S W}^{F}\right]+\mu \mathbb{E}\left[\alpha_{j}^{P}\right]
$$

is a constant which accounts for that the inefficient type engages in cost-padding and auditing is costly. Importantly, notice that the value of the constant depends on the type of the politician.

Furthermore, if $\psi^{\prime \prime \prime} \geq 0, \Phi$ is convex, which ensures that the regulator objective function is concave and the contractual solution is unique, as stated in the following Lemma:

Lemma 3. (Type 1 optima: cost-padding by type $\mathrm{H}$ only) There is a unique Type 1 optimum (indicated with superscript $C P H$ ) which is as follows: $C_{H}^{C P H}=\beta_{H}-e^{S B}+\alpha$, $t_{H}^{C P H}=\psi\left(e^{S B}\right)-\mathbb{E}\left[\alpha_{j}^{F}\right] ; C_{L}^{C P H}=\beta_{L}-e^{F B}, t_{L}^{C P H}=\psi\left(e^{F B}\right)+\Phi\left(e_{H}^{S B}\right)$ where

$$
e^{S B}:(1-\nu)(1+\lambda)\left[1-\psi^{\prime}\left(e^{S B}\right)\right]=\nu \lambda \Phi^{\prime}\left(e^{S B}\right), e^{S B}<e^{F B}
$$

\footnotetext{
${ }^{27}$ Notice that $a_{H}^{*}=a_{L}^{m}=\alpha$ respects Lemma 1: for a given cost $C=C_{H}, a_{L}^{m} \geq a_{H}^{*}$.
} 
The value function of the politician is

$$
\mathbb{E}\left[U_{j}^{C P H}\right]=\mathbb{E}\left[U^{S B}\right]+(1-\nu) G_{j}\left(\alpha, \rho_{j}\right)-(1+\lambda) c \rho_{j}
$$

with

$$
\mathbb{E}\left[U^{S B}\right]=\nu\left[S-(1+\lambda)\left(\beta_{L}-e^{F B}+\psi\left(e^{F B}\right)\right)-\lambda \Phi\left(e^{S B}\right)\right]+(1-\nu)\left[S-(1+\lambda)\left(\beta_{H}-e^{S B}+\psi\left(e^{S B}\right)\right)\right]
$$

where $e^{S B}$ and $\mathbb{E}\left[U^{S B}\right]$ are as in the second-best solution of the standard procurement problem without cost-padding (see Laffont and Tirole (1993), Ch.1).

The interpretation is as usual in second-best contracts (see e.g., Baron and Myerson (1982) and Maskin and Riley (1984)). In order to reduce the rent $\Phi\left(e_{H}\right)$ that he needs to give to the efficient type not to mimic the inefficient type, the principal needs to distort downward the effort required from the inefficient type $e_{H}$. A marginal decrease in the inefficient type's effort involves a second-order loss in the politician's utility, while the relaxation of the $I C$ constraint of the efficient type generates a first-order gain.

The $C P H$ optimum occurs in equilibrium if and only if two conditions are satisfied namely that 1 ) the inefficient type does find it profitable to engage in cost-padding when accepting his contract $\left(C_{H}^{C P H}, t_{H}^{C P H}\right)$; and 2) the efficient type does not want to deviate to cost-padding when mimicking the inefficient type. Therefore - using condition (20) and $\beta_{H}-C_{H}^{C P H}+\alpha=e^{S B}$ and $\beta_{L}-C_{L}^{C P H}=e^{F B}-$ iff

$$
\psi\left(e^{F B}+\alpha\right)-\psi\left(e^{F B}\right)>\mathbb{E}\left[\alpha_{j}^{F}\right] \geq \psi\left(e^{S B}\right)-\psi\left(e^{S B}-\alpha\right)
$$

Expressing condition (28) with respect to the detection technology $\rho$, yields the following result:

Lemma 4. (Occurrence of the $\mathrm{CPH}$ optimum) Under politician $j \in\{B, S\}$, the $C P H$ optimum occurs iff $\underline{\rho}_{j}<\rho \leq \bar{\rho}_{j}{ }^{28}$, where

$$
\begin{gathered}
\underline{\rho}_{j}=\frac{\alpha-\left[\psi\left(e^{F B}+\alpha\right)-\psi\left(e^{F B}\right)\right]}{\alpha} K_{j} \\
\bar{\rho}_{j}=\frac{\alpha-\left[\psi\left(e^{S B}\right)-\psi\left(e^{S B}-\alpha\right)\right]}{\alpha} K_{j} \\
\text { with } K_{j}= \begin{cases}1, & \text { if } j=B \\
\frac{2 \mu}{\mu+1}, & \text { if } j=S\end{cases}
\end{gathered}
$$

With a similar reasoning, the following results can be established concerning the three other possible types of equilibria.

\footnotetext{
${ }^{28}$ Notice that since $e^{F B}>e^{S B}$ and $\psi^{\prime}(e)-\psi^{\prime}(e-\alpha)>0, \underline{\rho}_{j}<\bar{\rho}_{j}$.
} 
Lemma 5. (Type 2 optima: cost-padding by type L only) Two mutually exclusive Type 2 optima are possible. When type $L$ does not want to pad cost while mimicking $H$, the $C P L 1$ solution emerges: $C_{H}^{C P L 1}=\beta_{H}-e^{S B}, t_{H}^{C P L 1}=\psi\left(e^{S B}\right) ; C_{L}^{C P L 1}=\beta_{L}-e^{F B}+\alpha$, $\mathbb{E}\left[t_{L}^{C P L 1}\right]=\psi\left(e^{F B}\right)-\mathbb{E}\left[\alpha_{j}^{F}\right]+\Phi\left(e^{S B}\right)$. When type $L$ wants to pad costs while mimicking $H$, the CPL2 solution emerges: $C_{H}^{C P L 2}=\beta_{H}-\bar{e}, t_{H}^{C P L 2}=\psi(\bar{e}) ; C_{L}^{C P L 2}=\beta_{L}-e^{F B}+\alpha$, $\mathbb{E}\left[t_{L}^{C P L 2}\right]=\psi\left(e^{F B}\right)-\mathbb{E}\left[\alpha_{j}^{F}\right]+\Gamma(\bar{e})$, where

$$
\begin{aligned}
& \Gamma(\bar{e}) \equiv \psi(\bar{e})-\psi(\bar{e}-\Delta \beta+\alpha)+\mathbb{E}\left[\alpha_{j}^{F}\right] \text { with } \\
& \bar{e}: \psi^{\prime}(\bar{e})=1-\frac{\lambda}{1+\lambda} \frac{\nu}{1-\nu} \Gamma^{\prime}(\bar{e}), e^{S B}<\bar{e}<e^{F B}
\end{aligned}
$$

The value functions of the politician are $\mathbb{E}\left[U_{j}^{C P L 1}\right]=\mathbb{E}\left[U^{S B}\right]-(1+\lambda) c \rho_{j}$ and $\mathbb{E}\left[U_{j}^{C P L 2}\right]=$ $\mathbb{E}\left[U^{S B}\right]+\nu G_{j}\left(\alpha, \rho_{j}\right)-(1+\lambda) c \rho_{j}$.

Proof. In the Appendix 7.1.

The intuition why the optimal effort required from the inefficient type (i.e.,the power of incentives) is higher in the CPL2 solution than in CPL1, and, consequently, is higher the rent to be given to the efficient type $\Gamma(\bar{e})>\Phi\left(e^{S B}\right)$, is as follows (also see LT, pag. $527)$. Increasing $e_{H}$ is more attractive when the efficient type would like to engage in costpadding when mimicking the inefficient type, due to the fact that cost-padding increases the marginal disutility of the efficient type of mimicking the inefficient type, $\psi^{\prime}\left(e_{H}-\Delta \beta+\alpha\right)$, with respect to the case without cost-padding, $\psi^{\prime}\left(e_{H}-\Delta \beta\right)$. This implies that a marginal increase in $e_{H}$ increases the rent of the efficient type by less than when the efficient type does not want to pad costs $\left(\Gamma^{\prime}\left(e_{H}\right)<\Phi^{\prime}\left(e_{H}\right)\right)$.

However it is proved that:

Lemma 6. (Occurrence of Type 2 optima) There is no parameters configuration such that either the CPL1 or the CPL2 solution can be unambiguously said to occur in equilibrium.

Proof. In the Appendix 7.2.

Lemma 7. (Type 3 optima: cost-padding by both types) There is a unique Type 3 optimum (indicated with superscript $C P$ ) which is as follows: $C_{H}^{C P}=\beta_{H}-e^{S B}+\alpha$, $\mathbb{E}\left[t_{H}^{C P}\right]=\psi\left(e^{S B}\right)-\mathbb{E}\left[\alpha_{j}^{F}\right] ; C_{L}^{C P}=\beta_{L}-e^{F B}+\alpha, \mathbb{E}\left[t_{L}^{C P}\right]=\psi\left(e^{F B}\right)-\mathbb{E}\left[\alpha_{j}^{F}\right]+\Phi\left(e^{S B}\right)$. The value function of the politician is $\mathbb{E}\left[U_{j}^{C P}\right]=\mathbb{E}\left[U^{S B}\right]+G_{j}\left(\alpha, \rho_{j}\right)-(1+\lambda) c \rho_{j}$.

Proof. In the Appendix 7.3.

Lemma 8. (Occurrence of the CP optimum) Under politician $j \in\{B, S\}$ the CP optimum occurs in equilibrium iff $\rho \leq \hat{\rho}_{j}$, where

$$
\hat{\rho}_{j}=\frac{\alpha-\left[\psi\left(e^{F B}\right)-\psi\left(e^{F B}-\alpha\right)\right]}{\alpha} K_{j}
$$

Proof. In the Appendix 7.4. 
Lemma 9. (Type 4 optima: no cost-padding) Two mutually exclusive Type 4 optima are possible. When type $L$ does not want to pad cost while mimicking type $H$, the NC1 solution emerges: $C_{H}^{N C 1}=\beta_{H}-e^{S B}, t^{N C 1}=\psi\left(e^{S B}\right) ; C_{L}^{N C 1}=\beta_{L}-e^{F B}, t_{L}^{N C 1}=\psi\left(e^{F B}\right)+\Phi\left(e^{S B}\right)$. When type $L$ wants to pad cost while mimicking type $H$, the $N C 2$ solution emerges: $C_{H}^{N C 2}=$ $\beta_{H}-\bar{e}, t_{H}^{N C 2}=\psi(\bar{e}) ; C_{L}^{N C 2}=\beta_{L}-e^{F B}, \mathbb{E}\left[t_{L}^{N C 2}\right]=\psi\left(e^{F B}\right)+\Gamma(\bar{e})$.

The value functions of the politician are $\mathbb{E}\left[U_{j}^{N C 1}\right]=\mathbb{E}\left[U_{j}^{N C 2}\right]=\mathbb{E}\left[U^{S B}\right]-(1+\lambda) c \rho_{j}$.

Proof. In the Appendix 7.5.

The intuition why the optimal effort required from the inefficient type (i.e.,the power of incentives) is higher in the $N C 2$ solution than in $N C 1$, and, consequently, is higher the rent to be given to the efficient type is the same as the one provided for Type 2 optima.

Lemma 10. (Occurrence of the $N C 1$ optimum) Under politician $j \in\{B, S\}$ the $N C 1$ solution occurs in equilibrium iff $\rho>\rho_{j}^{\prime}$ where

$$
\rho_{j}^{\prime}=\frac{\alpha-\left[\psi\left(e^{S B}-\Delta \beta+\alpha\right)-\psi\left(e^{S B}-\Delta \beta\right)\right]}{\alpha} K_{j}
$$

Proof. See Appendix 7.6.

Lemma 11. (Occurrence of the $N C 2$ optimum) Under politician $j \in\{B, S\}$ the $N C 2$ solution occurs in equilibrium iff $\rho_{j}<\rho \leq \tilde{\rho}_{j}$ where:

$$
\begin{gathered}
\rho_{j}=\frac{\alpha-[\psi(\bar{e}+\alpha)-\psi(\bar{e})]}{\alpha} K_{j} \\
\tilde{\rho}_{j}=\frac{\alpha-[\psi(\bar{e}-\Delta \beta+\alpha)-\psi(\bar{e}-\Delta \beta)]}{\alpha} K_{j}
\end{gathered}
$$

Proof. See Appendix 7.7.

It is now possible to gather the result of the optimal contracts analysis under incomplete information. The contractual solutions can be ranked according to the level of embezzlement which is induced in equilibrium (more technically, whether and which type of firm pad costs in equilibrium).

Proposition 2. (Optimal procurement contracts) Under incomplete information, four different contractual optima can occur depending on the value of the detection probability $\rho$ : (i) for $0<\rho \leq \underline{\rho}_{j}$ only the CP solution occurs; (ii) for $\underline{\rho}_{j}<\rho \leq \hat{\rho}_{j}$ both the CP and the CPH solutions can occur; (iii) for $\hat{\rho}_{j}<\rho \leq \rho_{j}$ only the CPH solution occurs; (iv) for $\rho_{j}<\rho \leq \bar{\rho}_{j}$ both the CPH and the NC2 solutions can occur; ( $v$ ) for $\bar{\rho}_{j}<\rho \leq \tilde{\rho}_{j}$ only the NC2 solution can occur; (vi) for $\tilde{\rho}_{j}<\rho \leq \rho_{j}^{\prime}$ no solution can occur; (vii) for $\rho_{j}^{\prime}<\rho<1$ only the NC1 solution can occur ${ }^{29}$.

\footnotetext{
${ }^{29}$ The gap and the overlapping of solutions are due to the fact that $\bar{e} \neq e^{S B}$ and shrink as $\bar{e} \rightarrow e^{S B}$.
} 
As intuitive, the lower the $\rho$, the higher the level of embezzlement which occurs in equilibrium: when the probability of detecting cost-padding is low, both types find it profitable to engage in cost-padding when accepting equilibrium contracts $(C P$ optimum occurs); when the detection probability increases a bit, the inefficient type still finds it profitable to do cost-padding, but the efficient type may not, since it is asked to exert a higher equilibrium effort which makes cost-padding more costly in terms of extra disutility of effort (however, the efficient type would pad costs were it to mimic the inefficient type, since it could finance the extra effort by means of the economy in disutility which it gains from mimicking) (CPH optimum occurs); when the detection probability rises further, neither the inefficient type wants to do equilibrium cost-padding, but the efficient type would still have an incentive to pad costs when mimicking ( $N C 2$ optimum occurs); when the detection probability becomes even higher, neither the efficient type finds it profitable to pad costs when mimicking the inefficient type ( $N C 1$ optimum occurs). Proposition 2 is represented in Figure 1 below.

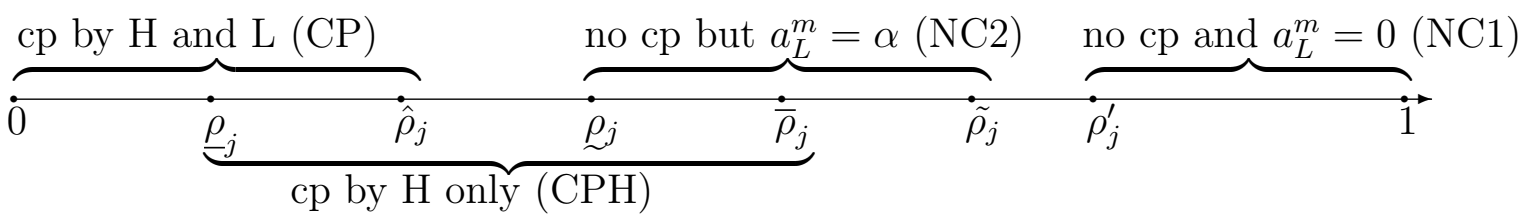

Figure 1: Transition of contractual optima depending on $\rho$

\section{Optimal auditing policy}

The last step is to analyze the politician's optimal auditing policy on the basis of optimal contracts derived in last section. Therefore, while the detection probability $\rho$ has so far been regarded as a parameter, in this section it is endogenized. The politician will choose the auditing level that maximizes his stepwise continuation payoff function: ${ }^{30}$

$$
\mathbb{E}\left[U_{j}^{*}(\rho)\right]= \begin{cases}\mathbb{E}\left[U_{j}^{C P}\right]=\mathbb{E}\left[U^{S B}\right]+G_{j}\left(\alpha, \rho_{j}\right)-(1+\lambda) c \rho_{j}, & \text { if } \rho_{j} \in\left(0, \underline{\rho}_{j}\right] \\ \mathbb{E}\left[U_{j}^{C P H}\right]=\mathbb{E}\left[U^{S B}\right]+(1-\nu) G_{j}\left(\alpha, \rho_{j}\right)-(1+\lambda) c \rho_{j}, & \text { if } \rho_{j} \in\left(\hat{\rho}_{j}, \rho_{j}\right] \\ \mathbb{E}\left[U_{j}^{N C 2}\right]=\mathbb{E}\left[U^{S B}\right]-(1+\lambda) c \rho_{j}, & \text { if } \rho_{j} \in\left(\bar{\rho}_{j}, \tilde{\rho}_{j}\right] \\ \mathbb{E}\left[U_{j}^{N C 1}\right]=\mathbb{E}\left[U^{S B}\right]-(1+\lambda) c \rho_{j}, & \text { if } \rho_{j} \in\left(\rho_{j}^{\prime}, 1\right)\end{cases}
$$

Obviously, if type $j$ politician were to prefer a cost-padding-free contractual solution, he would always prefer the $N C 2$ optimum, since it is the cheapest option in terms of cost of auditing; and he would always induce the $N C 2$ optimum by choosing some value of

\footnotetext{
${ }^{30}$ Each type of politician has strict preferences (depending on the parameter of the models) over the solutions. Therefore, the politician will never choose values of $\rho$ that sustain the overlapping between solutions.
} 
detection probability arbitrarily close to $\bar{\rho}_{j}$, i.e., the minimum level of auditing that still deters both types from padding costs (while, had auditing been costless $c=0$, the politician would have been indifferent between the $N C 1$ and $N C 2$ solutions and would have optimally picked any of the values of $\rho$ sustaining either of the two solution).

Things are slightly less straightforward in case type $j$ politician were to prefer a contractual solution with cost-padding. In the following, let us disregard solution $C P H$ and focus on solution $C P$ only, since that does not change the main results and intuitions (it can be checked that, provided $\nu$ is high enough, the $C P$ solution is always preferred to the $C P H$ solution). The optimal auditing choice for inducing $C P$ depends on the sign of the difference $G_{j}\left(\alpha, \rho_{j}\right)-(1+\lambda) c \rho_{j}$, which in turns determines the sign of $\frac{\partial\left[G_{j}\left(\alpha, \rho_{j}\right)-(1+\lambda) c \rho_{j}\right]}{\partial \rho}$. If the sign is positive, politician type $j$ gets an extra positive continuation payoff from inducing a contractual solution with cost-padding, and maximizes this extra gain with high levels of auditing. On the other hand, if the difference is negative, which also implies $\frac{\partial\left[G_{j}\left(\alpha, \rho_{j}\right)-(1+\lambda) c \rho_{j}\right]}{\partial \rho}<0$, a contractual solution with cost-padding reduces the value for the politician, and he minimizes this extra loss with low levels of auditing.

Straightforward calculations yield that under a relatively selfish politician $(j=S)$ the difference is positive $\left(G_{S}\left(\alpha, \rho_{S}\right)-(1+\lambda) c \rho_{S}>0\right)$ only if $\mu>1+D(\lambda, \alpha, c)$, where $D(\lambda, \alpha, c)=\frac{(1+\lambda) 2 c+(\lambda-1) \alpha+\sqrt{(1+\lambda)^{2}(\alpha+2 c)^{2}-4 \alpha^{2} \lambda}}{2 \alpha}>0$. Therefore the politician needs to be very selfish to prefer cost-padding. In particular, it must be the case that the marginal benefit of cost-padding in terms of increased private utility $(\mu)$ is higher than the marginal extra cost for consumers in terms of distortionary taxation $(1+D(\lambda, \alpha, c)){ }^{31}$ In other words the politician cares more about his perspective bribe than about consumers paying more taxes due to increased project costs.

Notice that such an extremely selfish politician faces a trade-off when choosing the auditing level: on one hand he would prefer high auditing, that allows him to detect costpadding more often, hence increasing his expected share of embezzled money; on the other hand, stricter auditing deters the firm from engaging in cost-padding in the first place, decreasing the politician's expected share, so that he needs to restrict auditing. ${ }^{32}$ Therefore, the optimal detection choice for such a selfish politician will be $\underline{\rho}_{S}$, that is the highest level of detection probability that is still consistent with both types of firm having an incentive to engage in cost-padding.

Less than very selfish politicians $(\mu \leq 1+D(\lambda, \alpha, c))$, do not like cost-padding per se and care more about the extra tax burden for consumers than about the bribe. Therefore, in principle they would like to induce the cost-padding free contractual solution by choosing a strict auditing. However, since auditing is costly, they might still prefer to induce the cost-padding solution since the loss in social welfare for deterring cost padding at a much higher (and hence costly) auditing level can be higher than the loss due to inducing cost-padding at a lower auditing cost. This would never happen in case of costless auditing, since the politician would be always able to deter cost-padding at no cost. Therefore, a

\footnotetext{
${ }^{31}$ The marginal cost is higher than the pure marginal cost of distortionary taxation $(1+\lambda)$, since, due to both imperfect auditing and bargaining, the politician does not always get the total of embezzled money.

${ }^{32}$ A similar trade-off occurs in Dittmann (2006).
} 
less opportunist politician is subject to a different trade-off: on one hand a higher auditing level allows him to deter cost-padding (which increases consumers welfare by reducing the cost that consumers need to pay from firm's misbehavior), but a higher auditing implies high costs of auditing (which decreases consumers' welfare).

Straightforward calculations show that moderately selfish politicians $(1<\mu \leq 1+$ $D(\lambda, \alpha, c))$ will always induce cost-padding, choosing an arbitrary small level of auditing $\rho_{\epsilon}$, because it is cheaper, in terms of extra burden from distortionary taxation, than preventing cost-padding. A relatively benevolent politician $(j=B)$ will induce the costpadding solution only when the cost of auditing is high enough $\left(c>\frac{\lambda}{(1+\lambda)} \frac{\rho_{\epsilon}}{\bar{\rho}-\rho_{\epsilon}}\right)$, and in that case he will minimize the loss by choosing $\rho_{\epsilon}$. If instead the cost of auditing is not very high, he will prevent cost-padding by choosing $\bar{\rho}_{B}$ (i.e., the lowest auditing level which sustain the $N C 2$ solution).

Therefore, depending on the values of parameters, four different PBE can arise, as summarized in the following proposition:

Proposition 3. (Optimal auditing policy and PBE) Under a relatively benevolent politician $(j=B)$ two PBE can arise. If the cost of auditing is low enough, the "cost-paddingfree" PBE will arise, where the politician prevents cost-padding by choosing a sufficiently strict auditing level. Otherwise (c high enough) the "lesser of two evils" PBE will arise, where the politician induces cost-padding by choosing an arbitrary small level of auditing. If the politician is relatively selfish $(j=S)$ two PBE can arise. If he is very selfish the "cost-padding love" PBE will arise, where he induces cost-padding by choosing a sufficiently lax auditing level. If he is less selfish the "lesser of two evils" PBE will arise.

The formal characterization of the full set of PBE is provided in Appendix 7.8.

Some further interesting insights come from comparative statics on the necessary condition for the "cost-padding love" equilibrium $(\mu>1+D(\lambda, \alpha, c))$, as stated in the next proposition.

Proposition 4. (Comparative statics) The "cost-padding love" equilibrium is relative more likely to occur in equilibrium i) the less distortionary is taxation ( $\left.\frac{\partial D}{\partial \lambda}>0\right)$; ii) the lower is the cost of auditing $\left(\frac{\partial D}{\partial c}>0\right)$; and iii) the higher is the extent of embezzlement $\left(\frac{\partial D}{\partial \alpha}<0\right)$.

The interpretation of Proposition 4 is as follows. First, a decrease in the distortions of taxation reduces the social cost of cost-padding, which implies that also moderately opportunist politicians will have an incentive to let cost-padding occur. In the limit case of a perfectly efficient fiscal system (i.e., $\lambda=0$ ) all relatively selfish politicians (i.e., $\forall \mu>1$ ) will allow cost-padding to occur. A similar effect emerges from a decrease in the cost of auditing, which also reduces the tax burden for consumers. On the other hand, the higher the extent of embezzlement the higher the incentive for the politician to care more about his own bribe relative to the higher cost for taxpayers.

Notice that since politicians need to weaken the auditing technology in order to induce cost-padding, the model predicts an endogenous substitutability between auditing and State capacity: if the State works well the politician will choose poor auditing, while if the State 
works poorly he will choose strong auditing. An interesting extension to implement in this direction, is to endogenize $\lambda$ in order to check whether a more selfish politician would invest more in State capacity, in order to steal more, while a more benevolent ruler would invest less (see e.g., Besley and Persson (2009)).

Also, notice that the extent to which the politician is able to pursue his private agenda rather than social welfare depends on the effectiveness of the political system, in terms of the political accountability it manages to create. Therefore $\mu$ can be interpreted as a measure of (exogenous) political accountability: the more efficient is the political system, i.e., the more accountable are politicians, the lower is $\mu$ (see e.g., Shapiro and Willig (1990)). This interpretation allows for a second result, namely that a decrease in $\lambda$ (or $c$ ) must be more than counterbalanced by a decrease in $\mu$ in order to make cost-padding less easier to occur. This result can be explained in the light of Acemoglu (2010)'s discussion about State capacity. ${ }^{33}$ A reduction in the distortion of taxation has ambiguous effects on welfare: on one hand it has a direct positive effect insofar it improves redistribution and allocation of resources. On the other hand however, it has an indirect negative effect insofar it increases the potential benefits of ruling the State, so that pursuing personal interest becomes more attractive for the politician: the higher the improvement in efficiency the lower degree of selfishness is needed to find it convenient for the politician to prefer the cost-padding regime. ${ }^{34}$ Therefore my results appear to confirm Acemoglu (2010)'s insight that an improvement in State capacity (like a more efficient fiscal system) is not good per se (as instead argued by Besley and Persson (2010) - who neglected the impact that an increase in State capacity has on political equilibrium) but it is beneficial only if it comes from or is coincident to an increase in the political accountability of politicians.

Propositions 3 and 4 confirm the conjecture under investigation, namely that the occurrence of cost-padding in the execution of public projects can be explained as a problem of political corruption. In LT - where the politician is benevolent and the auditing technology is exogenous - cost-padding can emerge in optimal contracts only due to incomplete information (i.e., when preventing cost-padding is too costly in terms of the extra-rents the politicians need to pay), and (bureaucratic) corruption can never occur in equilibrium, since the principal always makes a take-it-or-leave-it offer to the corruptible bureaucrat. On the other hand, in this model, due to the endogenization of the auditing policy, costpadding and (political) corruption can occur in equilibrium and are ultimately choices of the politician. Relatively benevolent politicians, by choosing a relatively strict auditing policy, prevent cost-padding from occurring. Conversely, sufficiently selfish politicians, who are eager to get a share of the embezzled funds, choose a relatively lax auditing policy in order to induce the firm to pad costs, and enter in corrupt transactions with the firm whenever they have the chance to do so. This result is consistent with the "mixed" nature of the politician, who cares both about social welfare and private utility. Since cost-padding implies a higher cost for consumers in terms of distortionary taxation, only a politician who is eager enough is willing to allow for cost-padding to occur. Costly auditing adds to

\footnotetext{
${ }^{33}$ Also see Acemoglu et al. (2011).

${ }^{34}$ In Acemoglu (2010) an increase in the potential benefits of controlling the state intensifies the political conflict aimed at capturing this control.
} 
the result, in the sense that a moderate politician (who cares more about social welfare) might prefer to induce cost padding at a lower (auditing) cost than preventing it, as this is less detrimental for social welfare.

A policy implication suggested by these results is that the law should provide for the auditing of contract execution to be responsibility of an external independent authority rather than of the purchasing authority. Under the current legislation (e.g., Directives 2004/17/EC, 2004/18/EC for the EU), the bureaucrat that in practice is responsible for the auditing is an employee of the purchasing authority. The same is true for the bureaucrats in charge of contract design and contract award. In this legislative context, corrupt higher level politicians are able to influence employment decisions in the authority, and place complicit officials to induce malfeasance and to guarantee their own participation in corrupt deals (OECD (2006)).

If, on the other hand, the law provided for the monitoring of contract execution to be responsibility of an external independent authority (possibly combined with random forensic audits), it would be much more difficult for the politician to exert his influence (see e.g., Ware et al. (2007)). Also, in order to reduce the interference of politicians in contract design and award activities, a higher degree of centralization and aggregation of procurement may help, for example enhancing the role of regional or national procurement agencies (see e.g., Dimitri et al. (2006) and references therein). Again, it would be much harder for the politician to influence a larger and independent authority. Finally, also standardized contracting may prove useful in this sense (see e.g., Iossa and Martimort (2014)).

\section{Conclusion and future work}

In this paper I have provided a novel economic explanation for the occurrence of embezzlement in the execution of public contracts. I argued that at the core of the phenomenon is a problem of political corruption: selfish politicians at the top of the procurement hierarchy may be interested in obtaining a share of the money embezzled by the contracting firm and, hence, may create incentives for the firm to pad costs.

To investigate this conjecture, I built on the agency regulatory model of cost-padding in Laffont and Tirole (1993), to allow for the principal to be partially selfish and to be the main responsible party for both procurement contracts and for the auditing policy. Depending on his degree of selfishness, the politician decides both how strict the auditing of contract execution should be and, in case evidence of cost-padding is found, whether to enter a corrupt transaction with the firm i.e., hide evidence in exchange of a share of the embezzled money.

I found that a relatively benevolent politician - provided the cost of auditing is sufficiently low - chooses a relatively strict auditing policy, thereby preventing the firm from engaging in cost-padding; conversely, a sufficiently selfish politician, by choosing a relatively lax auditing policy, creates an incentive for embezzlement in optimal contracts and, conditional upon detection, enters in a corrupt transaction with the firm. If the cost of 
auditing is too high, even a relatively benevolent politician might prefer to allow for costpadding, thus saving on the cost of auditing in order to minimize the welfare loss. This result is consistent with the "mixed" nature of the politician, who cares both about social welfare and his private utility. Since cost-padding implies a higher cost for consumers in terms of distortionary taxation, only a politician who is eager enough is willing to allow for cost-padding to occur.

In addition, an interesting comparative statics result that emerged is that an improvement in the efficiency of the fiscal system makes cost-padding easier to occur. This is due to the fact that since the social cost of cost-padding (in terms of distortionary taxation) is lower, less selfish politicians are also tempted to engage in corruption. Consequently, since politicians need to reduce auditing in order to induce cost-padding, the model also predicts endogenous substitutability between auditing and State capacity.

A possible policy implication of these results is that the law should provide for the auditing of contract execution to be the responsibility of an external, independent authority rather than a bureaucrat from the purchasing entity, as it is the case under the current legislation. This way it would be harder for corrupt top politicians to abet the employment of complicit bureaucrats in the purchasing entity and, consequently, to induce embezzlement.

Despite its relative simplicity, my model produced interesting results. Still, there is a number of dimensions along which the analysis could be further developed. First, it would be interesting to relax the assumption of automatic enforcement of contracts and announcements to see how issues of contract renegotiation and credibility problems add up to existing results. In particular, this would allow for the information revelation issues to have more bite in the model, and to analyze the problem of credibility underlying the politician's auditing choice. ${ }^{35}$

Second, to further enhance the descriptive power of the modelization of auditing, it would be possible to explicitly separate the roles of the politician and of the auditing bureaucrat, hence allowing for the bureaucrat to have independent motives and behavior. This could be done by adopting the three-tier agency structure of classical auditing models, but still allowing for both the bureaucrat and the politician to be corruptible.

Third, it would be interesting to see what would happen when the politician's type is private information. In particular, a possible relevant extension would be to analyze the combined effect of this informational assumption and the introduction in the model of a third "benevolent" player (like the judicial system, the constituency, or the media) that can punish the politician in case of misbehavior. In this case, the third player could use the information that is revealed by the contract and the auditing choices of the politician to make inference about the politician's type. ${ }^{36}$ Also, the politician himself might want to

\footnotetext{
${ }^{35}$ For example, an opportunist politician could announce a strict auditing to look good to the public, but then implement a lax one to induce cost-padding by the firm. The issue of credibility would hence add a further constraint to the problem of consumers in the political accountability extension (see e.g., Khalil and Lawarrée (1995)).

${ }^{36} \mathrm{In}$ an extension of this paper, which is available upon request, I considered how the politician's optimal behavior would change when some form of political accountability is introduced. In particular, I considered the role of elections as a disciplining device (see e.g., Barro (1973) and Ferejohn (1986)). I found that a
} 
bias the procurement policy as a way to signal his type (see e.g., Acemoglu et al. (2013)). Another possibility, suggested by the result that a more selfish politician has a lower bargaining power in the sharing of the embezzled money, would be to investigate whether the politician has any incentive to pretend to have a smaller selfishness (but still compatible with corruption, $\mu>1$ ) in order to get a larger bribe in Nash bargaining.

Fourth, as suggested by the endogenous substitutability result, it would be interesting to endogenize the efficiency of the fiscal system $\lambda$ with respect to the selfishness $\mu$, in order to assess the conjecture whether a more selfish politician would invest more in State capacity, in order to embezzle more, while a more benevolent would invest less.

Last, it would be also interesting to study the problem from the opposite viewpoint, namely to endogenize the politician's selfishness $\mu$ with respect to $\lambda$ and in general the institutions that constrain the politician's behavior. ${ }^{37}$

\section{Appendix}

\subsection{Proof of Lemma 5}

In this case, the cost level of the inefficient type is $C_{H}=\beta_{H}-e_{H}$. If type $L$ mimics type $H$, both $a_{L}^{m}=0$ and $a_{L}^{m}=\alpha$ are admissible by Lemma 1 . Therefore, the $I C_{L}$ is less trivial to define than before, insofar it is needed that the rent of the efficient type is such that he does not want to mimic the inefficient type neither without engaging in cost-padding:

$$
I C_{L}\left(a_{L}^{m}=0\right): \mathbb{E}\left[\Pi_{L}\right]=t_{L}+\mathbb{E}\left[\alpha_{j}^{F}\right]-\psi\left(\beta_{L}-C_{L}+\alpha\right) \geq t_{H}-\psi\left(\beta_{L}-C_{H}\right)
$$

nor with engaging in cost-padding

$$
I C_{L}\left(a_{L}^{m}=\alpha\right): \mathbb{E}\left[\Pi_{L}\right] \geq t_{H}+\mathbb{E}\left[\alpha_{j}^{F}\right]-\psi\left(\beta_{L}-C_{H}+\alpha\right)
$$

By using the fact that constraint $I R_{H}$ will bind at the optimum as usual i.e., $\Pi_{H}=$ $t_{H}-\psi\left(e_{H}\right)=0$, constraints (39) and (40) can be rewritten respectively as

$$
\mathbb{E}\left[\Pi_{L}\right] \geq \Phi\left(e_{H}\right)
$$

and

$$
\mathbb{E}\left[\Pi_{L}\right] \geq \Gamma\left(e_{H}\right)
$$

where $\Phi\left(e_{H}\right) \equiv \psi\left(e_{H}\right)-\psi\left(e_{H}-\Delta \beta\right)$ and $\Gamma\left(e_{H}\right) \equiv \psi\left(e_{H}\right)-\psi\left(e_{H}-\Delta \beta+\alpha\right)+\mathbb{E}\left[\alpha_{j}^{F}\right]$.

Depending on which of the constraints (41) and (42) binds at the optimum, different

selfish politician will embezzle less money than in absence of voting. The cost for consumers, in terms of (distortionary) taxation, of keeping the politician accountable is higher the more opportunist is the politician, the lower is the (exogenous) value of remaining in office and the lower is the distortionary power of taxation.

${ }^{37} \mathrm{~A}$ second possible way to endogenize the politician's self-interest would be "motivational" and would consider the role of psychological and social factors on the intrinsic motivation and self-regulation of the politician (see e.g., Bénabou and Tirole (2002), Bénabou and Tirole (2003) and Bénabou and Tirole (2006)). 
solutions can emerge. To consider all possibilities the following maximization problem is set:

$$
\begin{array}{ll}
\max _{e_{H}, \mathbb{E}\left[\Pi_{L}\right]} & \mathbb{E}\left[U\left(e_{H}, \mathbb{E}\left[\Pi_{L}\right]\right)\right]=\nu\left[S-(1+\lambda)\left[\beta_{L}-e^{F B}+\psi\left(e^{F B}\right)\right]-\lambda \mathbb{E}\left[\Pi_{L}\right]\right] \\
& +(1-\nu)\left[S-(1+\lambda)\left[\beta_{H}-e_{H}+\psi\left(e_{H}\right)\right]\right]+\nu G_{j}\left(\alpha, \rho_{j}\right)-(1+\lambda) c \rho_{j}
\end{array}
$$

s.t.(41), (42)

where $G_{j}\left(\alpha, \rho_{j}\right)$ is the constant defined in (24). Writing constraints (41) and (42) in the form

$$
\begin{aligned}
& \Phi\left(e_{H}\right)-\mathbb{E}\left[\Pi_{L}\right] \leq 0 \\
& \Gamma\left(e_{H}\right)-\mathbb{E}\left[\Pi_{L}\right] \leq 0
\end{aligned}
$$

the Lagrangian for problem (43) is:

$$
\begin{aligned}
& \mathcal{L}=\nu\left[S-(1+\lambda)\left[\beta_{L}-e^{F B}+\psi\left(e^{F B}\right)\right]-\lambda \mathbb{E}\left[\Pi_{L}\right]\right]+ \\
& (1-\nu)\left[S-(1+\lambda)\left[\beta_{H}-e_{H}+\psi\left(e_{H}\right)\right]\right]+\xi\left[\mathbb{E}\left[\Pi_{L}\right]-\Phi\left(e_{H}\right)\right]+\zeta\left[\mathbb{E}\left[\Pi_{L}\right]-\Gamma\left(e_{H}\right)\right]
\end{aligned}
$$

where the constant $\nu G_{j}\left(\alpha, \rho_{j}\right)-(1+\lambda) c \rho_{j}$ is omitted and $\xi$ and $\zeta$ are the Lagrange multipliers of constraints (44) and (45) respectively.

Applying the Khun-Tucker necessary conditions (which in this case are also sufficient), four possible cases need to be considered, according to which of the constraints is binding:

Case 1 no constraint is binding: $\xi=0, \zeta=0$

Case 2 (44) binding, (45) not binding: $\xi>0, \zeta=0$

Case 3 (45) binding, (44) not binding: $\xi=0, \zeta>0$

Case 4 both constraints are binding: $\xi>0, \zeta>0$

Sublemma 1. Only Case 2 and Case 3 yield a solution.

Proof.

Case $1 \xi=0, \zeta=0$

The FOC relative to the variable $\mathbb{E}\left[\Pi_{L}\right]$ gives $-\nu \lambda=0$, which is clearly impossible (as expected, since the incentive compatibility constraint for the efficient type should be binding in equilibrium).

Case $2 \xi>0, \zeta=0(C P L 1)$ 
Provided that the following condition

$$
\Phi\left(e^{S B}\right) \geq \Gamma\left(e^{S B}\right)
$$

holds, the unique solution for this case is: $\left\{e^{C P L 1}=e^{S B} ; \mathbb{E}\left[\Pi_{L}^{C P L 1}\right]=\Phi\left(e^{S B}\right) ; \xi^{C P L 1}=\nu \lambda\right\}$, where

$$
e^{S B}: \psi\left(e^{S B}\right)=1-\frac{\lambda}{1+\lambda} \frac{\nu}{1-\nu} \Phi^{\prime}\left(e^{S B}\right)
$$

Case $3 \xi=0, \zeta>0(C P L 2)$

Provided that the following condition

$$
\Gamma(\bar{e}) \geq \Phi(\bar{e})
$$
where

holds, the unique solution for this case is $\left\{e^{C P L 2}=\bar{e} ; \mathbb{E}\left[\Pi_{L}^{C P L 2}\right]=\Gamma(\bar{e}) ; \zeta^{C P L 2}=\nu \lambda\right\}$,

$$
\bar{e}: \psi(\bar{e})=1-\frac{\lambda}{1+\lambda} \frac{\nu}{1-\nu} \Gamma^{\prime}(\bar{e})
$$

Case $4 \xi>0, \zeta>0$

The FOCs imply $\zeta^{4 *}<0$, impossible.

Therefore only Case 2 and Case 3 give solutions Q.E.D.

Sublemma 2. $\bar{e}>e^{S B}$.

Proof. Since $\Phi^{\prime}(e)>\Gamma^{\prime}(e) \quad \forall e \geq 0$, the result follows by inspection of the FOCs in (48) and (50).

Sublemma 3. The solutions found in Case 2 and Case 3 are mutually exclusive. Therefore for each regime there is a unique solution, which by virtue of the concavity of the problem is global.

Proof. Given Sublemma 2, it must be the case that if (47) holds for $e^{S B}$, it must hold also for $\bar{e}>e^{S B}$. Therefore, when (47) holds, (49) cannot hold. With a similar reasoning one can conclude that when (49) holds, (47) cannot hold. When $(47)$ holds, $\left(e^{S B}, \Phi\left(e^{S B}\right)\right)$ is the only maximizer, while when $(49)$ holds, $(\bar{e}, \Gamma(\bar{e}))$ is the only maximizer Q.E.D

\subsection{Proof of Lemma 6}

The solution $C P L 1$ occurs in equilibrium if and only if $L$ wants to engage in cost-padding when not mimicking and does not want to engage in cost-padding when mimicking, i.e., if and only if the following double condition is met:

$$
\psi\left(e^{F B}\right)-\psi\left(e^{F B}-\alpha\right) \leq \mathbb{E}\left[\alpha_{j}\right]<\psi\left(e^{S B}-\Delta \beta+\alpha\right)-\psi\left(e^{S B}-\Delta \beta\right)
$$


(where use was made of $(20)$ and $\beta_{L}-C_{L}^{C P L 1}+\alpha=e^{F B}$ and $\beta_{H}-C_{H}^{C P L 1}=e^{S B}$ ). ${ }^{38}$ Notice that for this condition to ever hold, it is needed that:

$$
\psi\left(e^{F B}\right)-\psi\left(e^{F B}-\alpha\right)<\psi\left(e^{S B}-\Delta \beta+\alpha\right)-\psi\left(e^{S B}-\Delta \beta\right)
$$

By using the fact that the difference $\psi(e)-\psi(e-\alpha)$ is increasing, it can be assessed that this condition is never verified for $\Delta \beta \geq \alpha$. If $\Delta \beta<\alpha$ is impossible to determine unambiguously which side of (52) is greater.

On the other hand, the solution CPL2 occurs in equilibrium if and only if 1 ) the efficient type does finds it profitable to do cost-padding both when choosing her contract and when mimicking the inefficient type; and 2) the inefficient type does not want to deviate to costpadding (in this case Lemma 1 does not help). That is, the three following conditions need to hold simultaneously (using $\beta_{L}-C^{C P L 2}+\alpha=e^{F B}$ and $\beta_{H}-C^{C P L 2}=\bar{e}$ )

$$
\mathbb{E}\left[\alpha_{j}\right] \geq \psi\left(e^{F B}\right)-\psi\left(e^{F B}-\alpha\right)
$$

(i.e., $L$ wants to engage in cost-padding when not mimicking)

$$
\mathbb{E}\left[\alpha_{j}\right] \geq \psi(\bar{e}-\Delta \beta+\alpha)-\psi(\bar{e}-\Delta \beta)
$$

(i.e., $L$ wants to engage in cost-padding when mimicking ${ }^{39}$ )

$$
\mathbb{E}\left[\alpha_{j}\right]<\psi(\bar{e}+\alpha)-\psi(\bar{e})
$$

(i.e., $H$ does not want to engage in cost-padding)

Again, by using the fact that the difference $\psi(e)-\psi(e-\Delta \beta)$ is increasing, it can be established that the three conditions cannot hold simultaneously for $\Delta \beta \geq 2 \alpha$, since for that configuration of parameters it is the case that the RHS of condition (53) is bigger than the RHS of condition (54), but is smaller than the RHS of (55). On the other hand, for $\Delta \beta<2 \alpha$ nothing unambiguous can be said Q.E.D.

\subsection{Proof of Lemma 7}

In this case the cost level of the inefficient type is $C_{H}=\beta_{H}-e_{H}+\alpha$. Again, it is known from Lemma 1 that $a_{L}^{m}=\alpha$. Therefore, the relevant $I C_{L}$ and $I R_{H}$ constraints are respectively:

$$
\begin{gathered}
\mathbb{E}\left[\Pi_{L}\right]=t_{L}+\mathbb{E}\left[\alpha_{j}\right]-\psi\left(\beta_{L}-C_{L}+\alpha\right) \geq t_{H}+\mathbb{E}\left[\alpha_{j}^{F}\right]-\psi\left(\beta_{L}-C_{H}+\alpha\right) \\
\mathbb{E}\left[\Pi_{H}\right]=t_{H}+\mathbb{E}\left[\alpha_{j}^{F}\right]-\psi\left(\beta_{H}-C_{H}+\alpha\right) \geq 0
\end{gathered}
$$

It is immediate to check that the relaxed maximization problem for the politician is identical to the Type 1 case (equation (23)), with the only difference that now the constant

\footnotetext{
${ }^{38}$ Notice that the condition on the right corresponds to condition (47).

${ }^{39}$ Notice that condition (54) corresponds to (49).
} 
$G_{j}\left(\alpha, \rho_{j}\right)$ (defined in (24)) enters in the politician's objective function with probability 1 , since both types engage in cost-padding. Therefore the equilibrium effort for the inefficient type will be the same, and the solution the one stated in the main text Q.E.D.

\subsection{Proof of Lemma 8}

The $C P$ occurs in equilibrium if and only if both types find it profitable to do cost-padding when accepting their own contracts. Therefore, the following two conditions need to hold (using $\beta_{L}-C_{L}+\alpha=e^{F B}$ and $\beta_{H}-C_{H}+\alpha=e^{S B}$ ):

$$
\begin{aligned}
& \mathbb{E}\left[\alpha_{j}\right] \geq \psi\left(e^{F B}\right)-\psi\left(e^{F B}-\alpha\right) \\
& \mathbb{E}\left[\alpha_{j}\right] \geq \psi\left(e^{S B}\right)-\psi\left(e^{S B}-\alpha\right)
\end{aligned}
$$

which, since the RHS of (58) is larger than the RHS of (59), implies the result in 8.

\subsection{Proof of Lemma 9}

Also in this case, as in subsection 7.1, both $a_{L}^{m}=0$ and $a_{L}^{m}=\alpha$ are admissible by Lemma 1 when the efficient type mimics the inefficient type. Therefore, again a double $I C_{L}$ is needed:

$$
\begin{gathered}
I C_{L}\left(a_{L}^{m}=0\right): \mathbb{E}\left[\Pi_{L}\right]=t_{L}-\psi\left(\beta_{L}-C_{L}\right) \geq t_{H}-\psi\left(\beta_{L}-C_{H}\right) \\
I C_{L}\left(a_{L}^{m}=\alpha\right): \mathbb{E}\left[\Pi_{L}\right] \geq t_{H}+\mathbb{E}\left[\alpha_{j}^{F}\right]-\psi\left(\beta_{L}-C_{H}+\alpha\right)
\end{gathered}
$$

and the maximization problem is the same as in (43), apart from constant $\nu G_{j}\left(\alpha, \rho_{j}\right)$ which here is missing since type $L$ is not padding costs at the optimum. Consequently, also the contractual solutions will be the same, as stated in the main text Q.E.D.

\subsection{Proof of Lemma 10}

The $N C 1$ solution occurs in equilibrium if and only if the efficient type does not find it profitable to engage in cost-padding neither when mimicking the inefficient type nor when not mimicking, i.e., if and only if the two following conditions (where use was made of $\beta_{H}-C_{H}^{N C 1}=e^{S B}$ and $\left.\beta_{L}-C_{L}^{N C 1}=e^{F B}\right)$ hold:

$$
\begin{gathered}
\mathbb{E}\left[\alpha_{j}^{F}\right]<\psi\left(e^{S B}-\Delta \beta+\alpha\right)-\psi\left(e^{S B}-\Delta \beta\right) \\
\mathbb{E}\left[\alpha_{j}^{F}\right]<\psi\left(e^{F B}+\alpha\right)-\psi\left(e^{F B}\right)
\end{gathered}
$$

Notice that by virtue of Lemma 1 , condition (62) guarantees that the inefficient type neither will deviate to cost-padding when accepting $\left(C_{H}^{N C 1}, t_{H}^{N C 1}\right)$.

Since the RHS of condition (62) is smaller than the RHS of condition (63), the former is necessary and sufficient for the solution $N C 1$ to occur in equilibrium. Solving this condition for $\rho$ yields the result stated in the main text Q.E.D. 


\subsection{Proof of Lemma 11}

The $N C 2$ solution occurs in equilibrium if and only if the efficient type does want to engage in cost-padding when mimicking the inefficient type but not when not mimicking and the inefficient type does not want to engage in cost-padding (Lemma 1 does not help in this case), i.e., if and only if the following system of conditions hold:

$$
\begin{gathered}
\mathbb{E}\left[\alpha_{j}^{F}\right] \geq \psi(\bar{e}-\Delta \beta+\alpha)-\psi(\bar{e}-\Delta \beta) \\
\mathbb{E}\left[\alpha_{j}^{F}\right]<\psi\left(e^{F B}+\alpha\right)-\psi\left(e^{F B}\right) \\
\mathbb{E}\left[\alpha_{j}^{F}\right]<\psi(\bar{e}+\alpha)-\psi(\bar{e})
\end{gathered}
$$

Notice that condition (66) implies condition (65), so that, by solving the relevant conditions with respect to $\rho$, the result in Lemma 11 follows Q.E.D.

\subsection{Perfect Bayesian Equilibria of the Game}

Under a very selfish politician $(\mu>1+D(\lambda, \alpha, c))$ only the "cost-padding love" PBE can arise:

$$
\left\{\begin{array}{l}
s_{P}^{*}=\left\{\rho^{*}=\rho_{S},\left(C_{i}^{*}, t_{i}^{*}\right)=\left(C_{i}^{C P}, t_{i}^{C P}\right), E D^{*}=\text { enter }\right\} \\
s^{*}\left(\beta_{H}\right)=\left\{C D^{*}=\text { accept }, a_{H}^{*}=\alpha, E D^{*}=\text { enter }\right\} \\
s^{*}\left(\beta_{L}\right)=\left\{C D^{*}=\text { accept }, a_{L}^{*}=\alpha, E D^{*}=\text { enter }\right\} \\
B^{*}=\left\{b(\emptyset)\left(\beta_{L}\right)=\nu, b(\emptyset)\left(\beta_{H}\right)=1-\nu, b\left(\rho^{*},\left(C_{i}^{C P}, t_{i}^{C P}\right), \text { accept }\right)\left(\beta_{i}\right)=1\right\}
\end{array}\right.
$$

Under a moderately selfish politician $(1<\mu \leq 1+D(\lambda))$ only the "lesser of the two evils" PBE arises:

$$
\left\{\begin{array}{l}
s_{P}^{*}=\left\{\rho^{*}=\rho_{\epsilon},\left(C_{i}^{*}, t_{i}^{*}\right)=\left(C_{i}^{C P}, t_{i}^{C P}\right), E D^{*}=\text { enter }\right\} \\
s^{*}\left(\beta_{H}\right)=\left\{C D^{*}=\text { accept, } a_{H}^{*}=0 ; E D^{*}=\text { enter }\right\} \\
s^{*}\left(\beta_{L}\right)=\left\{C D^{*}=\text { accept }, a_{L}^{*}=0, E D^{*}=\text { enter }\right\} \\
B^{*}=\left\{b(\emptyset)\left(\beta_{L}\right)=\nu, b(\emptyset)\left(\beta_{H}\right)=1-\nu ; b\left(\rho^{*},\left(C_{i}^{C P}, t_{i}^{C P}\right), \text { accept }\right)\left(\beta_{i}\right)=1\right\}
\end{array}\right.
$$

Under a relatively benevolent politician $(1 \leq \mu)$ if $c>\frac{\lambda}{(1+\lambda)} \frac{\rho_{\epsilon}}{\bar{\rho}-\rho_{\epsilon}}$ only the "lesser of the two evils" PBE arises

$$
\left\{\begin{array}{l}
s_{P}^{*}=\left\{\rho^{*}=\rho_{\epsilon},\left(C_{i}^{*}, t_{i}^{*}\right)=\left(C_{i}^{C P}, t_{i}^{C P}\right), E D^{*}=\text { not enter }\right\} \\
s^{*}\left(\beta_{H}\right)=\left\{C D^{*}=\text { accept }, a_{H}^{*}=0, E D^{*}=\text { enter }\right\} \\
s^{*}\left(\beta_{L}\right)=\left\{C D^{*}=\text { accept }, a_{L}^{*}=0, E D^{*}=\text { enter }\right\} \\
B^{*}=\left\{b(\emptyset)\left(\beta_{L}\right)=\nu, b(\emptyset)\left(\beta_{H}\right)=1-\nu ; b\left(\rho^{*},\left(C_{i}^{C P}, t_{i}^{C P}\right), \text { accept }\right)\left(\beta_{i}\right)=1\right\}
\end{array}\right.
$$


while if $c \leq \frac{\lambda}{(1+\lambda)} \frac{\rho_{\epsilon}}{\bar{\rho}-\rho_{\epsilon}}$ only the "cost-padding-free" PBE arises

$$
\left\{\begin{array}{l}
s_{P}^{*}=\left\{\rho^{*}=\bar{\rho}_{B},\left(C_{i}^{*}, t_{i}^{*}\right)=\left(C_{i}^{N C 2}, t_{i}^{N C 2}\right), E D^{*}=\text { not enter }\right\} \\
s^{*}\left(\beta_{H}\right)=\left\{C D^{*}=\text { accept }, a_{H}^{*}=0, E D^{*}=\text { enter }\right\} \\
s^{*}\left(\beta_{L}\right)=\left\{C D^{*}=\text { accept, } a_{L}^{*}=0, E D^{*}=\text { enter }\right\} \\
B^{*}=\left\{b(\emptyset)\left(\beta_{L}\right)=\nu, b(\emptyset)\left(\beta_{H}\right)=1-\nu ; b\left(\rho^{*},\left(C_{i}^{N C 2}, t_{i}^{N C 2}\right), \text { accept }\right)\left(\beta_{i}\right)=1\right\}
\end{array}\right.
$$

\section{References}

Acemoglu, D. (2010). Institutions, factor prices, and taxation: Virtues of strong states? American Economic Review, 100(2):115-19.

Acemoglu, D., Egorov, G., and Sonin, K. (2013). A political theory of populism. The Quarterly Journal of Economics, 128(2):771-805.

Acemoglu, D., Ticchi, D., and Vindigni, A. (2011). Emergence and persistence of inefficient states. Journal of the European Economic Association, 9(2):177-208.

Acemoglu, D. and Verdier, T. (2000). The choice between market failures and corruption. American Economic Review, 90(1):194-211.

Aidt, T. (2003). Economic analysis of corruption: a survey. Economic Journal, 113(491):F632-F652.

Alesina, A. and Tabellini, G. (2007). Bureaucrats or politicians? part i: A single policy task. American Economic Review, 97(1):169-179.

Alesina, A. and Tabellini, G. (2008). Bureaucrats or politicians? part ii: Multiple policy tasks. Journal of Public Economics, 92(3-4):426-447.

Auriol, E. (2006). Corruption in procurement and public purchase. International Journal of Industrial Organization, 24(5):867-885.

Bandiera, O., Prat, A., and Valletti, T. (2009). Active and passive waste in government spending: Evidence from a policy experiment. American Economic Review, 99(4):12781308.

Banfield, E. C. (1975). Corruption as a feature of governmental organization. Journal of Law and Economics, 18(3):587-605.

Baron, D. P. and Besanko, D. (1984). Regulation, asymmetric information, and auditing. RAND Journal of Economics, 15(4):447-470.

Baron, D. P. and Myerson, R. B. (1982). Regulating a monopolist with unknown costs. Econometrica, 50(4):911-30. 
Barro, R. (1973). The control of politicians: An economic model. Public Choice, 14(1):1942.

Becker, G. S. and Stigler, G. J. (1974). Law enforcement, malfeasance, and compensation of enforcers. The Journal of Legal Studies, 3(1):1-18.

Bénabou, R. and Tirole, J. (2002). Self-confidence and personal motivation. The Quarterly Journal of Economics, 117(3):871-915.

Bénabou, R. and Tirole, J. (2003). Intrinsic and extrinsic motivation. Review of Economic Studies, 70(3):489-520.

Bénabou, R. and Tirole, J. (2006). Belief in a just world and redistributive politics. The Quarterly Journal of Economics, 121(2):699-746.

Besley, T. (2007). Principled agents?: The political economy of good government. OUP Catalogue.

Besley, T. and Persson, T. (2009). The origins of state capacity: Property rights, taxation, and politics. American Economic Review, 99(4):1218-44.

Besley, T. and Persson, T. (2010). State capacity, conflict, and development. Econometrica, 78(1):1-34.

Boehm, F. and Olaya, J. (2006). Corruption in public contracting auctions: The role of transparency in bidding processes. Annals of Public and Cooperative Economics, $77(4): 431-452$.

Bolton, P. and Dewatripont, M. (2005). Contract theory. MIT press.

Bougheas, S. and Worrall, T. (2012). Cost padding in regulated monopolies. International Journal of Industrial Organization, 30(4):331-341.

Buchanan, J. and Tullock, G. (1962). The calculus of consent: Logical foundations of constitutional democracy. University of Michigan Press, Ann Arbor.

Burguet, R. and Che, Y.-K. (2004). Competitive procurement with corruption. RAND Journal of Economics, 35(1):50-68.

Burguet, R. and Perry, M. K. (2007). Bribery and favoritism by auctioneers in sealed-bid auctions. The B.E. Journal of Theoretical Economics, 7(1):1-27.

Celentani, M. and Ganuza, J.-J. (2002). Corruption and competition in procurement. European Economic Review, 46(7):1273-1303.

Chu, L. Y. and Sappington, D. E. (2007). A note on optimal procurement contracts with limited direct cost inflation. Journal of Economic Theory, 137(1):745-753. 
Compte, O., Lambert-Mogiliansky, A., and Verdier, T. A. (2005). Corruption and competition in procurement auctions. RAND Journal of Economics, 36(1):1-15.

Coviello, D. and Gagliarducci, S. (2010). Building political collusion: Evidence from procurement auctions. IZA Discussion Papers 4939, Institute for the Study of Labor (IZA).

Dhami, S. and Al-Nowaihi, A. (2007). Corruption and the provision of public output in a hierarchical asymmetric information relationship. Journal of Public Economic Theory, $9(4): 727-755$.

Di Tella, R. and Schargrodsky, E. (2003). The role of wages and auditing during a crackdown on corruption in the city of buenos aires. Journal of Law and Economics, 46(1):269292.

Dimitri, N., Dini, F., and Piga, G. (2006). When should procurement be centralized? In N. Dimitri, G. and G.Spagnolo, editors, Handbook of Procurement, pages 47-81. Cambridge University Press.

Dittmann, I. (2006). The optimal use of fines and imprisonment if governments do not maximize welfare. Journal of Public Economic Theory, 8(4):677-695.

Ferejohn, J. (1986). Incumbent performance and electoral control. Public Choice, 50(1):525.

Garoupa, N. and Klerman, D. (2002). Optimal law enforcement with a rent-seeking government. American Law and Economics Review, 4(1):116-140.

Golden, M. A. and Picci, L. (2005). Proposal for a new measure of corruption, illustrated with italian data. Economics \& Politics, 17(1):37-75.

Goldman, E., Rocholl, J., and So, J. (2013). Politically connected boards of directors and the allocation of procurement contracts. Review of Finance, 17(5):1617-1648.

Gradstein, M. (1993). Rent seeking and the provision of public goods. The Economic Journal, 103(420):pp. 1236-1243.

Grossman, G. M. and Helpman, E. (1994). Protection for sale. American Economic Review, 84(4):833-850.

Grossman, G. M. and Helpman, E. (2002). Special interest politics. MIT press.

Guasch, J. L. and Straub, S. (2009). Corruption and concession renegotiations.: Evidence from the water and transport sectors in latin america. Utilities Policy, 17(2):185-190. Corruption and Infrastructure Services.

Iossa, E. and Martimort, D. (2013). Corruption in public-private partnerships. In de Vries, P. and Yehoue, E., editors, The Routledge Companion to Public-Private Partnerships, pages 207-224. Routledge. 
Iossa, E. and Martimort, D. (2014). Corruption in ppps, incentives and contract incompleteness. CEIS Research Paper 317, Tor Vergata University, CEIS.

Khalil, F. and Lawarrée, J. (1995). Collusive auditors. The American Economic Review, $85(2): 442-446$.

Klitgaard, R. (1988). Controlling Corruption. University of California Press.

Kofman, F. and Lawarrée, J. (1996). On the optimality of allowing collusion. Journal of Public Economics, 61(3):383-407.

Laffont, J.-J. and Tirole, J. (1986). Using cost observation to regulate firms. Journal of Political Economy, 94(3):614-641.

Laffont, J.-J. and Tirole, J. (1991). Auction design and favoritism. International Journal of Industrial Organization, 9(1):9-42.

Laffont, J.-J. and Tirole, J. (1993). A Theory of Incentives in Procurement and Regulation, volume 12 of MIT Press Books. The MIT Press.

Laffont, J.-J. and Tirole, J. (2002). The Theory of Incentives: The Principal-Agent Model. Princeton University Press.

Lengwiler, Y. and Wolfstetter, E. G. (2006). Corruption in procurement auctions. In N. Dimitri, G. and G.Spagnolo, editors, Handbook of Procurement, pages 412-429. Cambridge University Press.

Maskin, E. and Riley, J. (1984). Monopoly with incomplete information. RAND Journal of Economics, 15(2):171-196.

Mookherjee, D. and Png, I. P. L. (1995). Corruptible law enforcers: How should they be compensated? Economic Journal, 105(428):145-59.

OECD (2006). Transparency and accountability as tools for promoting integrity and preventing corruption in procurement: Possibilities and limitations. OECD Papers Vol. 5/10, OECD.

OECD (2007). Bribery in public procurement: Methods, actors and counter-measures.

Osborne, M. J. and Rubinstein, A. (1994). A Course in Game Theory. The MIT Press.

Persson, T. and Tabellini, G. (2000). Political Economics. Explaining Economic Policy. MIT press.

Piga, G. (2011). A fighting chance against corruption in public procurement? In Sreide, T. and Rose-Ackerman, S., editors, International Handbook on the Economics of Corruption, volume 2. Edward Elgar, Cheltenham. 
Polinsky, A. M. and Shavell, S. (2001). Corruption and optimal law enforcement. Journal of Public Economics, 81(1):1-24.

Rose-Ackerman, S. (1975). The economics of corruption. Journal of Public Economics, $4(2): 187-203$.

Rose-Ackerman, S. (1999). Corruption and Government: Causes, Consequences, and Reform. Cambridge University Press.

Shapiro, C. and Willig, R. D. (1990). Economic rationales for the scope of privatization. In Suleimann, E. and Waterbury, J., editors, The Political Economy of Public Sector Reform and Privatization, pages 55-87. Oxford, Westview Press.

Shleifer, A. and Vishny, R. W. (1993). Corruption. The Quarterly Journal of Economics, 108(3):599-617.

Søreide, T. (2005). Grey zones and corruption in public procurement: Issues for consideration. In OECD, editor, Fighting Corruption and Promoting Integrity in Public Procurement. Oxford, Westview Press.

Tirole, J. (1992). Collusion and the theory of organizations. In Laffont, J., editor, Advances of Economic Theory, Sixth World Congress, vol. 2, pages 151-213. Cambridge University Press.

Transparency International, . (2006). Handbook for curbing corruption in public procurement. Technical report, Transparency International.

Ware, G. T., Moss, S., Campos, E., and Noone, G. (2007). Corruption in public procurement: a perennial challenge. In Campos, E. and Pradhan, S., editors, The Many Faces of Corruption: Tracking Vulnerabilities at the Sector Level, pages 295-334. The World Bank, Washington, DC. 